\title{
Power Geometric Operators of Hesitant Multiplicative Fuzzy Numbers and Their Application to Multiple Attribute Group Decision Making
}

\author{
Lei Wang, Mingfang Ni, Zhanke Yu, and Lei Zhu \\ College of Communications Engineering, PLA University of Science and Technology, Nanjing, Jiangsu 210007, China \\ Correspondence should be addressed to Lei Wang; iponly@126.com
}

Received 30 December 2013; Revised 9 April 2014; Accepted 9 April 2014; Published 6 May 2014

Academic Editor: Valentina Emilia Balas

Copyright (C) 2014 Lei Wang et al. This is an open access article distributed under the Creative Commons Attribution License, which permits unrestricted use, distribution, and reproduction in any medium, provided the original work is properly cited.

\begin{abstract}
Multiplicative relations are one of most powerful techniques to express the preferences over alternatives (or criteria). In this paper, we propose a wide range of hesitant multiplicative fuzzy power aggregation geometric operators on multiattribute group decision making (MAGDM) problems for hesitant multiplicative information. In this paper, we first develop some compatibility measures for hesitant multiplicative fuzzy numbers, based on which the corresponding support measures can be obtained. Then we propose several aggregation techniques, and investigate their properties. In the end, we develop two approaches for multiple attribute group decision making with hesitant multiplicative fuzzy information and illustrate a real world example to show the behavior of the proposed operators.
\end{abstract}

\section{Introduction}

In decision making, uncertainty and hesitancy are usually unavoidable problems. Preference relations are the most common techniques to express the preference information about a set of alternatives or criteria and can be roughly classified into two types: the fuzzy preference relations (Orlovsky) [1] (also called the reciprocal preference relations [2]) and the multiplicative preference relations (Saaty's 1-9 scale) [3]. The former is based on the 0.1-0.9 scale, which is a symmetrical distribution around 0.5, while the latter is based on Saaty's 1-9 scale which is a nonsymmetrical distribution around 1. With multiplicative preference representation, an expert's preferences on $X$ are described by a positive preference relation, $A^{k} \subset X \times X, A^{k}=\left[a_{i j}^{k}\right]$, where $a_{i j}^{k}$ indicates a ratio of preference intensity for alternative $x_{i}$ to that of $x_{j}$; that is, it is interpreted as $x_{i}$ is $a_{i j}^{k}$ times as good as $x_{j}$. Saaty [3] suggests measuring $a_{i j}^{k}$ using a ratio scale, and precisely the 1-9 scale: $a_{i j}^{k}=1$ indicates indifference between $x_{i}$ and $x_{j}$, $a_{i j}^{k}=9$ indicates that $x_{i}$ is absolutely preferred to $x_{j}$, and $a_{i j}^{k} \in 2,3, \ldots, 8$ indicates intermediate evaluations.
In real life, the information is usually distributed asymmetrically; the well-known law of diminishing marginal utility is the common phenomenon in economics, cluster problems in data mining [4]. It is known that the fuzzy rule-based control system is always established by designers with trial and error and based on their experience or some experiments [5]. We often encounter situations in which experts hesitate and irresolute between several values when providing the degree that an alternative is prior to another, owing to a lack of expertise or insufficient knowledge. The evaluation of the alternative is represented by several possible values rather than by a margin of error or a possibility distribution. For example, suppose that an organization that contains many decision makers is authorized to give a ranking a pair of alternatives (alternatives $A$ and $B$ ). Some of the decision makers provide an evaluation of 1 ( $A$ is equally preferred to $B$ ), some provide an evaluation of 5 or 7 ( $A$ is strongly preferred to $B$, but they are not sure the degree that the alternative $A$ is preferred to $B$ ), and the others provide an evaluation of 7 ( $A$ is very strongly preferred to $B$ ); the three groups of decision makers cannot persuade one another to change their opinions. In such cases, the evaluation cannot be represented by interval numbers, intuitionistic 
fuzzy numbers, interval-valued intuitionistic fuzzy numbers, linguistic variables, uncertain linguistic variables, or 2-tuples because the evaluation is not a convex combination or the interval between 1 and 7; instead, it consists simply of three possible values. Based on the above analysis, we can find that it is better to use the asymmetrical distributed scale to express the information in the hesitant fuzzy preference relation.

The objective in multiple attribute group decision making (MAGDM) problems is to find the most desirable alternative(s) among a set of feasible alternatives, based on the preferences provided by a group of experts [6]. The fundamental prerequisite of decision making is how to aggregate individual experts' preference information on alternatives. Information aggregation is a process that combines individual experts' preferences into an overall one by using a proper aggregation technique [7]. Aggregation operators are the most widely used tool for combining individual preference information into overall preference information and deriving collective preference values for each alternative. The investigation on information aggregation has received surprisingly extensive attention from practitioners and researchers due to its practical and academic significance. Yager proposed the ordered weighted averaging (OWA) operator [8] and developed the generalized OWA (GOWA) operator [9]. Li [10-12] proposed the generalized OWA operator with IFSs. Xu and Yager [13], $\mathrm{Xu}$ [14], and Wei [15] developed some geometric aggregation operators based on IFSs, such as the IF weighted geometric operator, the IF ordered weighted geometric operator, and the IF hybrid geometric (IFHG) operator. Xu and Wang [16] developed the induced generalized aggregation operators for IFSs. Wei and Zhao [17] researched some induced correlated aggregating operators with IF information. Su et al. [18] proposed the induced generalized intuitionistic fuzzy OWA operator. Xu [19] proposed some operational laws for IFNs based on algebraic $t$-conorm and $t$-norm and developed the intuitionistic fuzzy weighed averaging operator, the intuitionistic fuzzy ordered weighted averaging based on which $\mathrm{Xu}$ and Yager [9] gave some other aggregation operators combining the geometric mean. Xia and Xu [20] introduced a series of aggregation operators for hesitant fuzzy information and discussed the relationships among them. Then, $\mathrm{Xu}$ et al. [21] developed several series of aggregation operators for hesitant fuzzy information with the aid of quasi-arithmetic means. Qian et al. [22] extended HFSs by IFSs and referred to them as generalized HFSs (GHFSs) and redefined some basic operations of GHFSs.

In contrast with above aggregation, Yager [23] developed a power average (PA) operator and a power ordered weighted average (POWA) operator to provide aggregation tools for which the weight vectors depend on the input arguments and that allow the values being aggregated to support and reinforce one another. Motivated by Yager, Xu and Yager [24] proposed a power geometric (PG) operator and a power ordered weighted (POWG) operator. However, the arguments of these power aggregation operators are exact numerical values. In practice, we often encounter situations in which the input arguments cannot be expressed as exact numerical values. Zhou and Chen [25] presented the generalized power average (GPA) operator and the generalized power ordered weighted average (GPOWA) operator. Xu [26] and Zhou et al. [7] extended the PA, POWA, PG, and POWG operators to intuitionistic fuzzy environments and developed some intuitionistic fuzzy power aggregation operators. Zhang [27] developed a series of generalized intuitionistic fuzzy power geometric operators to aggregate input arguments that are intuitionistic fuzzy numbers and studied some desired properties of these aggregation operators and investigate the relationships among these operators. $\mathrm{Xu}$ and Cai [28] proposed the uncertain power average operators for aggregating interval fuzzy preference relations. Xu and Wang [29] developed 2-tuple linguistic power average (2TLPA) operator, 2-tuple linguistic weighted PA operator (2TLWPA), and 2TLPOWA operator. Wan [30] proposed PA operators of trapezoidal intuitionistic fuzzy numbers (TrIFNs) involving the power average operator of TrIFNs, the weighted power average operator of TrIFNs, the power ordered weighted average operator of TrIFNs, and the power hybrid average operator of TrIFNs. Zhang [31] developed a wide range of hesitant fuzzy power aggregation operators for hesitant fuzzy information, such as the hesitant fuzzy power average (HFPA) operators, the hesitant fuzzy power geometric (HFPG) operators, the generalized hesitant fuzzy power average (GHFPA) operators, the generalized hesitant fuzzy power geometric (GHFPG) operators, the weighted generalized hesitant fuzzy power average (WGHFPA) operators, the weighted generalized hesitant fuzzy power geometric (WGHFPG) operators, the hesitant fuzzy power ordered weighted average (HFPOWA) operators, the hesitant fuzzy power ordered weighted geometric (HFPOWG) operators, the generalized hesitant fuzzy power ordered weighted average (GHFPOWA) operators, and the generalized hesitant fuzzy power ordered weighted geometric (GHFPOWG) operators.

Up to now, a lot of work has been done about other preference relations, but little has been done about the hesitant multiplicative preference relations. Now, Xia and $\mathrm{Xu}$ [32] define the concept of hesitant fuzzy preference relation and introduce the hesitant multiplicative set. It is, therefore, necessary to extend the existing power aggregation operators to hesitant multiplicative fuzzy environments and to develop new power aggregation operators for aggregating hesitant multiplicative fuzzy information. The aim of this paper is to extend the power aggregation operators to hesitant multiplicative fuzzy environments. In this paper, we first review hesitant multiplicative fuzzy sets and hesitant multiplicative fuzzy numbers and then give some hesitant fuzzy multiplicative operations, such as union, intersection, and some arithmetic operation on their elements. We also introduce compatibility measures for HMFNs, which the corresponding support measures can be obtained. We further propose some hesitant multiplicative fuzzy power geometric aggregation operators and obtain some important conclusions.

To do this, the remainder of the paper is organized as follows. Section 2 presents some basic concepts related to HMFSs, HMFNs, and PG operator. In Section 3, we first give the compatibility measures for HMFNs. Then, we present a variety of hesitant multiplicative fuzzy power geometric 
operators, investigate some of their basic properties, and discuss the relationships between the various operators. In Section 4, we develop two approaches to multiple attribute group decision making in uncertain environments based on the proposed operators and in Section 5 we use a real world example to illustrate our algorithm. Finally, Section 6 concludes the paper with some remarks.

\section{Preliminaries}

2.1. Hesitant Fuzzy Sets and Fuzzy Multisets. Sometimes, it is difficult to determine the membership of an element into a fixed set and which may be caused by a doubt among a set of different values. For the sake of a better description of this situation, Torra introduced the concept of HFSs as a generalization of fuzzy sets [33].

Definition 1 (see [33]). Let $X$ be a fixed set, then we define hesitant fuzzy set (HFS) on $X$ is in terms of a function $h$ applied to $X$ returns a subset of $[0,1]$, and $h(x)$ a hesitant fuzzy element HFE.

Additionally, Torra considered the relationships between HFSs and fuzzy multisets. He proved that a HFS can be represented by a FMS and also proved that the union and the intersection of two corresponding FMSs do not correspond to the union and the intersection of two HFSs.

Multisets [33-36] are a generalization of crisp sets where multiple occurrences of an element are permitted and correspond to the case where the membership degrees to the multisets are not Boolean but fuzzy. Given $X=\{a, b, c, d\}$, $M=\{a, a, a, b, b, b, c, c\}$ is a multiset. The function count is defined over the elements of the reference set. It corresponds to the number of occurrences of the element; for example, $\operatorname{count}_{M}(a)=3$ and $\operatorname{count}_{M}(c)=2$. A fuzzy multiset is a multiset in which all the elements have a membership value. Formally, a fuzzy multiset on $X$ can be seen as a crisp multiset on $X \times[0,1]$. For example, given the $X$ above,

$M=\{(a, 0.3),(a, 0.3),(a, 0.4),(b, 0.7),(b, 0.8),(b, 0.9),(a$, $0.4),(a, 0.5)\}$ is a fuzzy multiset. Fuzzy multisets have been studied by Yager and Miyamoto. They have defined several operations. Yager has defined several basic operations [36].

Definition 2 (see $[33,36])$. Let $A$ and $B$ be two multisets and $a$ the element in the reference set, then

(1) addition, $\oplus$ : $\operatorname{count}_{A \oplus B}(a)=\operatorname{count}_{A}(a)+\operatorname{count}_{B}(b)$;

(2) union, $\mathrm{U}$ : $\operatorname{count}_{A \cup B}(a)=\max \left(\operatorname{count}_{A}(a), \operatorname{count}_{B}(b)\right)$;

(3) intersection, $\cap$ : $\operatorname{count}_{A \cap B}(a)=\min \left(\operatorname{count}_{A}(a)\right.$, $\left.\operatorname{count}_{B}(b)\right)$.

However, this definition comes into conflict with FSs. Miyamoto gave the corresponding solutions. His alternative definitions for fuzzy multisets rely on these membership sequences. Union and intersection are defined, respectively, as the pointwise maximum and minimum of the sequence; for example, given two sequences $s_{1}=\left\langle x_{1}, \ldots, x_{n}\right\rangle$ and $s_{2}=$ $\left\langle y_{1}, \ldots, y_{n}\right\rangle, s_{1} \vee s_{2}=\left\langle x_{1} \vee y_{1}, \ldots, x_{n} \vee y_{n}\right\rangle$. To operate correctly, the shorter sequence is extended by adding zeroes until the number of elements is equal in both sequences. This definition satisfies $[A \cup B]_{\alpha}=[A]_{\alpha} \cup[B]_{\alpha}$ for all $\alpha$, where $[A]_{\alpha}$ is the $\alpha$-cut of $A$.

Definition 3 (see [33]). Given a HFS $A$ on $X$, and $h(x)$ for all $x$ in $X$, then the HFS can be defined as a FMS: FMS $_{A}=$ $\bigoplus_{x \in X} \bigoplus_{\gamma \in h(x)}\{(x, \gamma)\}$.

\subsection{Hesitant Multiplicative Sets and Multiplicative Multisets}

Definition 4 (see [32]). Let $X$ be a fixed set, then a hesitant multiplicative set (HMS) $D$ on $X$ is described as

$$
D=\{\langle x, h(x)\rangle \mid x \in X\}
$$

in which $h(x)$ is a set of some values in $[1 / 9,9]$, denoting the possible membership degrees of the element $x \in X$ to the set $D$, where $\rho \in h(x), 1 / 9 \leq \rho \leq 9$. For convenience, $h(x)$ is called hesitant multiplicative numbers (HMNs), and $M$ is the set of all HMNs.

Definition 5 (see [32]). Given a HMN $h$, its lower and upper bounds are defined as below:

$$
\begin{aligned}
& \text { lowerbound: } \rho^{-} \in h^{-}(x)=\min \{\rho \mid \rho \in h(x)\} ; \\
& \text { upperbound: } \rho^{+} \in h^{+}(x)=\max \{\rho \mid \rho \in h(x)\} .
\end{aligned}
$$

Definition 6. Given a HMS $h, A_{\text {env }}(h)$ is called the envelope of $h$ which is represented by $\left(h^{-}, 1 / h^{+}\right)$, with $h^{-}$and $1 / h^{+}$being its lower and upper bounds, respectively.

Obviously, the pair of functions $h^{-}$and $1 / h^{+}$define an IMS $\left\{\left\langle x, \rho_{A}(h), \gamma_{A}(h)\right\rangle\right\}$, where $\rho_{A}(h)=h^{-}, \gamma_{A}(h)=h^{+}$.

Definition 7 (see [32]). Let $X=\left\{x_{1}, x_{2}, \ldots, x_{n}\right\}$ be $n$ alternatives, then a hesitant multiplicative preference relation is expressed as $A=\left(h_{i j}\right)_{n \times n}$, where $h_{i j}=\left\{\rho_{h_{i j}}\right\}$ is a HMN, and $\rho_{h_{i j}}$ indicates the intensity degree to which the alternative $x_{i}$ is preferred to $x_{j}$, which should satisfy the condition that

$$
\rho_{h_{i j}}=\rho_{h_{j i}}, \quad \rho_{h_{i i}}=1, \quad \frac{1}{9} \leq \rho_{h_{i j}} \leq 9 .
$$

It is noted that the fundamental element of a hesitant multiplicative preference relation is the HMFN. To compare two HMFNs, Xia and Xu [30] define a score value as follows.

Definition 8 (see [32]). Let $h_{i}=\left\{\rho_{h_{i}}\right\}(i=1,2)$ be any two HMNs, the score function of $h$ is defined as

$$
s(h)=\frac{1}{|h|}\left(\sum_{\rho \in h} \rho\right),
$$

where $|h|$ is the cardinalities of $h$, then

(i) if $s\left(h_{1}\right)>s\left(h_{2}\right)$, then $h_{1}$ is superior to $h_{2}$, denoted by $h_{1}>h_{2}$;

(ii) if $s\left(h_{1}\right)=s\left(h_{2}\right)$, then then $h_{1}$ is equivalent to $h_{2}$, denoted by $h_{1} \sim h_{2}$.

In this paper, we give another definition of the score value. 
Definition 9. Let $h_{i}=\left\{\rho_{h_{i}}\right\}(i=1,2)$ be any two HMFNs, a geometric score function of $h$ is defined as

$$
s^{g}(h)=\left(\prod_{\rho \in h} \rho\right)^{1 /|h|},
$$

where $|h|$ is the cardinalities of $h$, then

(i) if $s\left(h_{1}\right)>s\left(h_{2}\right)$, then $h_{1}$ is superior to $h_{2}$, denoted by $h_{1}>h_{2}$;

(ii) if $s\left(h_{1}\right)=s\left(h_{2}\right)$, then then $h_{1}$ is equivalent to $h_{2}$, denoted by $h_{1} \sim h_{2}$.

Example 10. Given three HMNs: $h_{1}=\{1 / 3,1 / 2\}, h_{2}=\{1 / 2$, $6\}$, and $h_{3}=\{1,4\}$, then

$$
\begin{gathered}
s\left(h_{1}\right)=0.4167, \quad s\left(h_{2}\right)=3.25, \quad s\left(h_{3}\right)=2, \\
s^{g}\left(h_{1}\right)=0.4082, \quad s^{g}\left(h_{2}\right)=1.7321, \quad s^{g}\left(h_{3}\right)=2 .
\end{gathered}
$$

If we use Xia' score function, $h_{2}>h_{3}>h_{1}$, and use our geometric score function, $h_{3}>h_{2}>h_{1}$, then we can get the following operational laws for HMFNs.

Definition 11 (see [32]). Given three HMSs represented by their membership functions $h, h_{1}$, and $h_{2}$, we define the complement represented $h^{c}$, the union represented by $h_{1} \cup h_{2}$, and the intersection represented by $h_{1} \cap h_{2}$ and they are also HMSs:

(1) complement: $h^{c}=\bigcup_{\rho \in h}\{1 / \rho\}$;

(2) union: $h_{1} \cup h_{2}=\bigcup_{\rho_{1} \in h_{1}, \rho_{2} \in h_{2}}\left\{\rho_{1} \vee \rho_{2}\right\}$;

(3) intersection: $h_{1} \cap h_{2}=\cap_{\rho_{1} \in h_{1}, \rho_{2} \in h_{2}}\left\{\rho_{1} \wedge \rho_{2}\right\}$.

Definition 12 (see [32]). Let $h_{1}$ and $h_{2}$ be two HMNs and $\lambda$ a positive real number, then:

(1) $h^{\lambda}=\bigcup_{\rho \in h}\left\{\rho^{\lambda} /\left((1+\rho)^{\lambda}-\rho^{\lambda}\right)\right\}$;

(2) $\lambda h=\bigcup_{\rho \in h}\left\{(1+\gamma)^{\lambda}-1\right\}$;

(3) $h_{1} \oplus h_{2}=\bigcup_{\rho_{1} \in h_{1}, \rho_{2} \in h_{2}}\left\{\left(\rho_{1}+1\right)\left(\rho_{2}+1\right)-1\right\}$;

(4) $h_{1} \otimes h_{2}=\bigcup_{\rho_{1} \in h_{1}, \rho_{2} \in h_{2}}\left\{\rho_{1} \rho_{2} /\left(\rho_{1}+\rho_{2}-1\right)\right\}$.

Theorem 13 (see [32]). Given three HMFNs, $h, h_{1}$, and $h_{2}$, then we have

(1) $h_{1}^{c} \cup h_{2}^{c}=\left(h_{1} \cap h_{2}\right)^{c}$;

(2) $h_{1}^{c} \cap h_{2}^{c}=\left(h_{1} \cup h_{2}\right)^{c}$;

(3) $\left(h^{c}\right)^{n}=(n h)^{c}$;

(4) $n\left(h^{c}\right)=\left(h^{n}\right)^{c}$;

(5) $h_{1}^{c} \oplus h_{2}^{c}=\left(h_{1} \otimes h_{2}\right)^{c}$;

(6) $h_{1}^{c} \otimes h_{2}^{c}=\left(h_{1} \oplus h_{2}\right)^{c}$.

Definition 14. Let $X$ be a fixed set, then a multiplicative multisets set (MMS) $D^{M}$ on $X$ is described as

$$
D^{M}=\left\{\left\langle x, h^{M}(x)\right\rangle \mid x \in X\right\} .
$$

For any $x \in X$, the set $h^{M}(x)$ is given by $h^{M}(x)=\left\{\rho_{h^{M}(x)}^{(1)}\right.$, $\left.\rho_{h^{M}(x)}^{(2)}, \ldots, \rho_{h^{M}(x)}^{\left(\left|h^{M}(x)\right|\right)}\right\}$, where $\left|h^{M}(x)\right|$ denotes the cardinality of $h^{M}(x)$ and $\rho_{h^{M}(x)}^{(i)} \in[1 / 9,9]$ for all $i \in\left\{1,2, \ldots,\left|h^{M}(x)\right|\right\}$. We also define $\rho_{h^{M}(x)}^{+}=\max \left\{\rho \mid \rho \in h^{M}(x)\right\}=$ $\max _{i=1,2, \ldots,\left|h^{M}(x)\right|}\left\{\rho_{h^{M}(x)}^{(i)}\right\}$.

Definition 15. Let $X=\left\{x_{1}, x_{2}, \ldots, x_{n}\right\}$ be $n$ alternatives, then a hesitant multiplicative preference relation is expressed as $A=\left(h_{i j}^{M}\right)_{n \times n}$, where $h_{i j}^{M}=\left\{\rho_{h_{i j}^{M}}^{(1)}, \ldots, \rho_{h_{i j}^{M}}^{\left(\left|h_{i j}^{M}\right|\right)}\right\}$ is a MMN, and $\rho_{h_{i j}^{M}}^{(k)}$ expresses for any $k \in\left\{1, \ldots,\left|h_{i j}^{M}\right|\right\}$ a degree of intensity to which alternative $x_{i}$ is preferred to $x_{j}$. Furthermore, it should hold that $\left|h_{i j}^{M}\right|=\left|h_{i j}^{M}\right|$ and that each element of $h_{j i}^{M}$ is the inverse of one element of $h_{i j}$, that is, $h_{i j}^{M}=\cup_{\rho \in h_{i j}^{M}}\{1 / \rho\}$, and $\rho_{h_{i j}^{M}}$ indicates the intensity degree to which the alternative $x_{i}$ is preferred to $x_{j}$.

If one wants to allow for repetition of a same value in the set, he/she can use the concept of multiplicative multisets set.

2.3. Power Aggregation Operators. Yager [23] introduced a nonlinear weighted average aggregation tool, which is called power average operator as follows.

Definition 16 (see [21]). The power average (PA) operator is the mapping PA: $R^{n} \rightarrow R$ defined by the following formula:

$$
\operatorname{PA}\left(a_{i} \mid i=1,2, \ldots, n\right)=\frac{\sum_{i=1}^{n}\left(1+T\left(a_{i}\right)\right) a_{i}}{\sum_{i=1}^{n}\left(1+T\left(a_{i}\right)\right)}
$$

where

$$
T\left(a_{i}\right)=\sum_{\substack{j=1 \\ j \neq i}}^{n} \operatorname{Sup}\left(a_{i}, a_{j}\right)
$$

and $\operatorname{Sup}\left(a_{i}, a_{j}\right)$ are the support for $a_{i}$ from $a_{j}$. The support satisfies the following three properties:

(1) $\operatorname{Sup}\left(a_{i}, a_{j}\right) \in[0,1]$;

(2) $\operatorname{Sup}\left(a_{i}, a_{j}\right)=\operatorname{Sup}\left(a_{j}, a_{i}\right)$;

(3) $\operatorname{Sup}\left(a_{i}, a_{j}\right) \geq \operatorname{Sup}\left(a_{s}, a_{t}\right)$ if $\left|a_{i}-a_{j}\right|<\left|a_{s}-a_{t}\right|$.

Based on the OWA operator and the PA operator, Yager defined a power ordered weighted average (POWA) operator as follows.

Definition 17 (see [23]). The power ordered weighted average (POWA) operator is the mapping PA: $R^{n} \rightarrow R$ defined by the following formula:

$$
\operatorname{POWA}\left(a_{i} \mid i=1,2, \ldots, n\right)=\sum_{i=1}^{n} u_{i} a_{i},
$$


where

$$
\begin{gathered}
u_{i}=g\left(\frac{R_{i}}{T V}\right)-g\left(\frac{R_{i-1}}{T V}\right), \quad R_{i}=\sum_{j=1}^{i} V_{\operatorname{index}(j)}, \\
T V=\sum_{i=1}^{n} V_{\text {index }(i)}, \\
V_{\text {index }(i)}=1+T\left(a_{\operatorname{index}(i)}\right) \\
T\left(a_{\operatorname{index}(i)}\right)=\sum_{\substack{j=1 \\
j \neq i}}^{n} \operatorname{Sup}\left(a_{\text {index }(i)}, a_{\text {index }(j)}\right) .
\end{gathered}
$$

In the above equations, $a_{\operatorname{index}(i)}$ is the $i$ th largest argument of all the arguments, $T\left(a_{\text {index }(i)}\right)$ denotes the support of the $i$ th largest argument by all the other arguments, $\operatorname{Sup}\left(a_{\operatorname{index}(i)}, a_{\operatorname{index}(j)}\right)$ indicates the support for $a_{\operatorname{index}(i)}$ from $a_{\text {index }(j)}$, and $g:[0,1] \rightarrow[0,1]$ is a basic unit-interval monotonic (BUM) function that has the following properties: (1) $g(0)=0$, (2) $g(1)=1$, (3) if $x>y$, then $g(x) \geq g(y)$.

Motivated by Yager [23] and based on the PA operator and the geometric mean, $\mathrm{Xu}$ and Yager [24] defined the power geometric (PG) operator.

Definition 18 (see [24]). The power geometric (PG) operator is the mapping PG: $R^{n} \rightarrow R$ defined by the following formula:

$$
\operatorname{PG}\left(a_{i} \mid i=1,2, \ldots, n\right)=\prod_{i=1}^{n} a_{i}^{\left(1+T\left(a_{i}\right)\right) / \sum_{i=1}^{n}\left(1+T\left(a_{i}\right)\right)},
$$

where $T\left(a_{i}\right)$ satisfies condition (12).

Definition 19 (see [24]). The power ordered weighted geometric (POWG) operator is the mapping PG: $R^{n} \rightarrow R$ defined by the following formula:

$$
\operatorname{POWG}\left(a_{i} \mid i=1,2, \ldots, n\right)=\prod_{i=1}^{n} a^{u_{i}},
$$

where $u_{i}$ satisfies condition (10).

\section{Hesitant Multiplicative Fuzzy Power Geometric Operators}

Fuzzy multisets are another generalization of fuzzy sets. They are based on multisets (elements can be repeated in a multiset). In fuzzy multisets, the membership can be partial (instead of Boolean as for standard multisets).

In this section, we extend the power aggregation operators to accommodate hesitant multiplicative fuzzy information as input. As we know, the support measure indicates the degree of similarity between two elements. We first introduce the concept of compatibility of HMFNs.

Compatibility is an efficient and important tool which can be used to measure the consensus of opinions within a group of decision makers [37]. It is noted that the number of values in different HMFNs may be different; let two HMFNs, $h_{1}$ and $h_{2}$, in most cases, $\left|h_{1}\right| \neq\left|h_{2}\right|$. Wang et al. [38] extended the shorter one by adding different values to get the correlation measures in dual hesitant fuzzy environments [39]. We should extend the shorter one until both of them have the same length when we compare them. To extend the shorter one, the best way is to add the same value several times in it. The selection of this value mainly depends on the decision makers' risk preferences. Optimists anticipate desirable outcomes and may add the maximum value, while pessimists expect unfavorable outcomes and may add the minimum value. For example, let $h_{1}=\{4,3,5 / 2\}$ and $h_{2}=$ $\{5,3\}$. To operate correctly, the optimist may extend $h_{2}=$ $\{5,3\}$ to $h_{2}=\{5,5,3\}$ and the pessimist may extend it as $h_{2}=\{5,3,3\}$. The same situation can also be found in many existing [40-42]. To operate correctly, we suppose that two HMFNs, $h_{1}$ and $h_{2}$, have the same length. We can also find that the values in a HMFN are out of order; we can arrange them in any order. For a $\operatorname{HMFN} h$, let $\sigma:(1,2,3, \ldots, n) \rightarrow$ $(1,2,3, \ldots, n)$ be a permutation satisfying $\rho_{\sigma_{(i)}} \leq \rho_{\sigma_{(i+1)}}, \rho \in$ $h, i=1,2, \ldots,|h|$.

We define the compatibility degree of HMFNs and investigate its properties, and some detailed analysis will be presented sequentially.

For two HMFNs, $h_{1}$ and $h_{2}$, the compatibility between $h_{1}$ and $h_{2}$, denoted by $C\left(h_{1}, h_{2}\right)$, should satisfy the following properties:

(1) $0<C\left(h_{1}, h_{2}\right) \leq 1$;

(2) $C\left(h_{1}, h_{2}\right)=1$ if only if $h_{1}=h_{2}$;

(3) $C\left(h_{1}, h_{2}\right)=C\left(h_{2}, h_{1}\right)$.

On the basis of the above properties, we give the following compatibility measures of HMFNs.

Definition 20. For two HMFNs, $h_{1}$ and $h_{2}$, the compatibility between $h_{1}$ and $h_{2}$, denoted by $C\left(h_{1}, h_{2}\right)$ is

$$
C\left(h_{1}, h_{2}\right)=\left(\prod_{\rho \in h}\left(\min \left\{\frac{\rho_{h_{1_{\sigma(i)}}}}{\rho_{h_{2 \sigma(i)}}} \frac{\rho_{h_{2_{\sigma(i)}}}}{\rho_{h_{1 \sigma(i)}}}\right\}\right)\right)^{1 /|h|} .
$$

Clearly, $h_{1}$ and $h_{2}$ are perfectly compatible if $h_{1}=h_{2}$; that is, $C\left(h_{1}, h_{2}\right)=1$. By contrast, $h_{1}$ and $h_{2}$ have the worst compatibility if $C\left(h_{1}, h_{2}\right) \rightarrow 1 / 81$. Thus, the bigger the value of $C\left(h_{1}, h_{2}\right)$, the better the compatibility of $h_{1}$ and $h_{2}$. Yager's power average operators are two nonlinear weighted aggregation tools, and the weight $w_{i}=\left(1+T\left(h_{i}\right)\right) / \sum_{i=1}^{n}(1+$ $T\left(h_{i}\right)$ ) of argument $h_{i}$ depends on all of the input arguments $h_{j}(j=1,2, \ldots, n)$ and allows the argument values to support each other in the aggregation process. Furthermore, based on Definitions 16 and 20, we can see the compatibility $C$ has the properties of a support function; hence, it can be regarded as a possible support function. Let $\operatorname{Sup}\left(h_{i}, h_{j}\right)=C\left(h_{1}, h_{2}\right)$ (it does not means the support function is unique and cannot be something else). The higher the compatibility is, the more they support each other.

Then, we investigate the power aggregation operators in hesitant multiplicative fuzzy environments. 


\subsection{Hesitant Multiplicative Fuzzy Power Geometric (HMFPG) Operators}

Definition 21. Let $h_{i}=\left\{\rho_{h_{i}}\right\}(i=1,2, \ldots, n)$ be a collection of HMFNs, hesitant multiplicative fuzzy power geometric (HMFPG) operators

$\operatorname{HMFPG}\left(h_{i} \mid i=1,2, \ldots, n\right)=\bigotimes_{i=1}^{n}\left(h_{i}^{\left(1+T\left(h_{i}\right)\right) / \sum_{i=1}^{n}\left(1+T\left(h_{i}\right)\right)}\right)$,

where

$$
\begin{gathered}
T\left(h_{i}\right)=\sum_{\substack{j=1 \\
j \neq i}}^{n} C\left(h_{i}, h_{j}\right), \\
C\left(h_{i}, h_{j}\right) \\
=\left(\prod_{\rho_{i} \in h_{i}, \rho_{j} \in h_{j}}\left(\min \left\{\frac{\rho_{h_{i_{\sigma(i)}}}}{\rho_{h_{j_{\sigma(i)}}}} \frac{\rho_{h_{j_{\sigma(i)}}}}{\rho_{h_{i_{\sigma(i)}}}}\right\}\right)\right)^{1 /|h|}, \\
|h|=\left|h_{i}\right|=\left|h_{j}\right|, \quad i, j=1,2, \ldots, n .
\end{gathered}
$$

If we restrict $\lambda$ to be a real number in $[0,1]$ in Definition 12, then the result would be always a HMN.

Theorem 22. Let $h_{i}=\left\{\rho_{h_{i}}\right\}(i=1,2, \ldots, n)$ be a collection of HMFNs, the aggregated value using the HMFPG operator is also a HMFN, and

$$
\begin{aligned}
\operatorname{HMFPG}\left(h_{i} \mid i\right. & =1,2 \ldots, n) \\
=\bigcup_{\rho_{i} \in h_{i}, 1,2, \ldots, n} & \left\{\left(\prod_{i=1}^{n}\left(\rho_{i}\right)^{\left(1+T\left(h_{i}\right)\right) / \sum_{i=1}^{n} T\left(h_{i}\right)}\right)\right. \\
& \times\left(\prod_{i=1}^{n}\left(1+\rho_{i}\right)^{\left(1+T\left(h_{i}\right)\right) / \sum_{i=1}^{n}\left(1+T\left(h_{i}\right)\right)}\right. \\
& \left.\left.-\prod_{i=1}^{n}\left(\rho_{i}\right)^{\left(1+T\left(h_{i}\right)\right) / \sum_{i=1}^{n}\left(1+T\left(h_{i}\right)\right)}\right)^{-1}\right\} .
\end{aligned}
$$

Proof. We shall find convenient $V_{i}=1+T\left(h_{i}\right)=1+$ $\sum_{j=1, j \neq i}^{n} C\left(h_{i}, h_{j}\right)=1+\sum_{j=1, j \neq i}^{n}\left(\prod_{\rho_{i} \in h_{i}, \rho_{j} \in h_{j}}\left(\min \left\{\rho_{h_{i \sigma(i)}} / \rho_{h_{j_{\sigma(i)}}}\right.\right.\right.$, $\left.\rho_{h_{j_{\sigma(i)}}}\left(\rho_{h_{i \sigma(i)}}\right\}\right)^{1 /|h|}$, and $w_{i}=V_{i} / \sum_{i=1}^{n} V_{i}$. Here, $w_{i}$ is a proper of weights, $w_{i} \geq 0$ and $\sum_{i=1}^{n} w_{i}=1$, then,
$\operatorname{HMFPG}\left(h_{i} \mid i=1,2, \ldots, n\right)=\bigotimes_{i=1}^{n} n_{i}^{w_{i}}$; by using mathematical induction on $n$.

Suppose above equality holds for $n=t$; that is,

$$
\begin{aligned}
& \operatorname{HMFPG}\left(h_{1}, h_{2}, \ldots, h_{t}\right) \\
& =\bigotimes_{i=1}^{t} h_{i}^{w_{i}} \\
& =\bigcup_{\rho_{1} \in h_{1}, \rho_{2} \in h_{2}, \ldots, \rho_{t} \in h_{t}}\left\{\frac{\prod_{i=1}^{t}\left(\rho_{i}\right)^{w_{i}}}{\prod_{i=1}^{t}\left(1+\rho_{i}\right)^{w_{i}}-\prod_{i=1}^{t}\left(\rho_{i}\right)^{w_{i}}}\right\},
\end{aligned}
$$

where

$$
\begin{aligned}
& w_{i} \\
& =\left(1+\sum_{\substack{j=1 \\
j \neq i}}^{n}\left(\prod \min \left(\left\{\frac{\rho_{h_{i_{\sigma(i)}}}}{\rho_{h_{j \sigma(i)}}}, \frac{\rho_{h_{j_{\sigma(i)}}}}{\rho_{h_{i \sigma(i)}}}\right\}\right)\right)^{1 /|h|}\right) \\
& \times\left(\sum _ { i = 1 } ^ { n } \left(1+\left(\prod _ { \rho _ { i } \in h _ { i } , \rho _ { j } \in h _ { j } } \left(\operatorname { m i n } \left\{\frac{\rho_{h_{i_{\sigma(i)}}}}{\rho_{h_{j_{\sigma(i)}}}},\right.\right.\right.\right.\right. \\
& \left.\left.\left.\left.\left.\frac{\rho_{h_{j_{\sigma(i)}}}}{\rho_{h_{i \sigma(i)}}}\right\}\right)\right)^{1 /|h|}\right)\right)^{-1}
\end{aligned}
$$

then

$$
\begin{aligned}
& \operatorname{HMFPG}\left(h_{1}, h_{2}, \ldots, h_{t}, h_{t+1}\right) \\
& =\bigcup_{\rho_{1} \in h_{1}, \rho_{2} \in h_{2}, \ldots, \rho_{t} \in h_{t}}\left\{\frac{\prod_{i=1}^{t}\left(\rho_{i}\right)^{w_{i}}}{\prod_{i=1}^{t}\left(1+\rho_{i}\right)^{w_{i}}-\prod_{i=1}^{t}\left(\rho_{i}\right)^{w_{i}}}\right\} \\
& \otimes h_{t+1}^{w_{t+1}} \\
& =\bigcup_{\rho_{1} \in h_{1}, \rho_{2} \in h_{2}, \ldots, \rho_{t} \in h_{t}}\left\{\frac{\prod_{i=1}^{t}\left(\rho_{i}\right)^{w_{i}}}{\prod_{i=1}^{t}\left(1+\rho_{i}\right)^{w_{i}}-\prod_{i=1}^{t}\left(\rho_{i}\right)^{w_{i}}}\right\} \\
& \otimes \bigcup_{\rho_{t+1} \in h_{t+1}}\left\{\frac{\left(\rho_{t+1}\right)^{w_{t+1}}}{\left(1+\rho_{t+1}\right)^{w_{t+1}}-\left(\rho_{t+1}\right)^{w_{t+1}}}\right\} \\
& =\bigcup_{\rho_{1} \in h_{1}, \rho_{2} \in h_{2}, \ldots, \rho_{t+1} \in h_{t+1}}\left\{\left(\frac{\prod_{i=1}^{t}\left(\rho_{i}\right)^{w_{i}}}{\prod_{i=1}^{t}\left(1+\rho_{i}\right)^{w_{i}}-\prod_{i=1}^{t}\left(\rho_{i}\right)^{w_{i}}}\right.\right. \\
& \left.\cdot \frac{\left(\rho_{t+1}\right)^{w_{t+1}}}{\left(1+\rho_{t+1}\right)^{w_{t+1}}-\left(\rho_{t+1}\right)^{w_{t+1}}}\right)
\end{aligned}
$$




$$
\begin{array}{r}
\times\left(\frac{\prod_{i=1}^{t}\left(\rho_{i}\right)^{w_{i}}}{\prod_{i=1}^{t}\left(1+\rho_{i}\right)^{w_{i}}-\prod_{i=1}^{t}\left(\rho_{i}\right)^{w_{i}}}\right. \\
+\frac{\left(\rho_{t+1}\right)^{w_{t+1}}}{\left(1+\rho_{t+1}\right)^{w_{t+1}}-\left(\rho_{t+1}\right)^{w_{t+1}}} \\
+\bigcup_{\rho_{1} \in h_{1}, \rho_{2} \in h_{2}, \ldots, \rho_{t+1} \in h_{t+1}}^{-1}\left\{\frac{\prod_{i=1}^{t+1}\left(\rho_{i}\right)^{w_{i}}}{\prod_{i=1}^{t+1}\left(1+\rho_{i}\right)^{w_{i}}-\prod_{i=1}^{t+1}\left(\rho_{i}\right)^{w_{i}}}\right\} ;
\end{array}
$$

that is, above equality holds for $n=k+1$. Thus the equality holds for all $n$.

Then we can investigate some desirable properties of the HMFPG operator.

Property 1. If all $C\left(h_{i}, h_{j}\right)=k, i \neq j,(i, j=1,2, \ldots, n)$, then

$$
\begin{aligned}
& \operatorname{HMFPG}\left(h_{1}, h_{2}, \ldots, h_{n}\right) \\
& =\bigcup_{\rho_{i} \in h_{i}, i=1,2, \ldots, n}\left\{\frac{\prod_{i=1}^{n} \rho_{i}^{1 / n}}{\prod_{i=1}^{n}\left(1+\rho_{i}\right)^{1 / n}-\prod_{i=1}^{n} \rho_{i}^{1 / n}}\right\} .
\end{aligned}
$$

Proof. If $C\left(h_{i}, h_{j}\right)=k$, for all $i \neq j, T\left(h_{i}\right)=$ $\sum_{j=1, j \neq i}^{n} C\left(h_{i}, h_{j}\right)=(n-1) k$

$$
\begin{aligned}
& \operatorname{HMFPG}\left(h_{i} \mid i=1,2, \ldots, n\right) \\
& =\bigotimes_{i=1}^{n} h_{i}^{\left(1+T\left(h_{i}\right)\right) / \sum_{i=1}^{n}\left(1+T\left(h_{i}\right)\right)} \\
& =\bigcup_{\rho_{1} \in h_{1}, \rho_{2} \in h_{2}, \ldots, \rho_{n} \in h_{n}}\left\{\left(\prod_{i=1}^{n} \rho_{i}^{\left(1+T\left(h_{i}\right)\right) / \sum_{i=1}^{n}\left(1+T\left(h_{i}\right)\right)}\right)\right. \\
& \times\left(\prod_{i=1}^{n}\left(1+\rho_{i}\right)^{\left(1+T\left(h_{i}\right)\right) / \sum_{i=1}^{n}\left(1+T\left(h_{i}\right)\right)}\right. \\
& \left.\left.-\prod_{i=1}^{n} \rho_{i}^{\left(1+T\left(h_{i}\right)\right) / \sum_{i=1}^{n}\left(1+T\left(h_{i}\right)\right)}\right)^{-1}\right\} \\
& =\bigcup_{\rho_{1} \in h_{1}, \rho_{2} \in h_{2}, \ldots, \rho_{n} \in h_{n}}\left\{\left(\prod_{i=1}^{n} \rho_{i}^{(1+(n-1) k) / \sum_{i=1}^{n}(1+(n-1) k)}\right)\right. \\
& \times\left(\prod_{i=1}^{n}\left(1+\rho_{i}\right)^{(1+(n-1) k) / \sum_{i=1}^{n}(1+(n-1) k)}\right.
\end{aligned}
$$

$$
\begin{aligned}
\left.\left.-\prod_{i=1}^{n} \rho_{i}^{(1+(n-1) k) / \sum_{i=1}^{n}(1+(n-1) k)}\right)^{-1}\right\} & \left\{\frac{\prod_{i=1}^{n} \rho_{i}^{1 / n}}{\prod_{i=1}^{n}\left(1+\rho_{i}\right)^{1 / n}-\prod_{i=1}^{n} \rho_{i}^{1 / n}}\right\} .
\end{aligned}
$$

Property 2 (commutativity). Let $h_{i}=\left\{\rho_{h_{i}}\right\}(i=1,2, \ldots, n)$ be a collection of HMFPG. Then, if $h_{i}^{\prime}=\left\{\rho_{h_{i}}^{\prime}\right\}(i=1,2, \ldots, n)$ any permutation of $h_{i}=\left\{\rho_{h_{i}}\right\}$, then we have

$$
\operatorname{HMFPG}\left(h_{1}, h_{2}, \ldots, h_{n}\right)=\operatorname{HMFPG}\left(h_{1}^{\prime}, h_{2}^{\prime}, \ldots, h_{n}^{\prime}\right) \text {. }
$$

However, the HMFPG operator is neither idempotent, bounded, nor monotonic, as illustrated by the following example.

Example. Let $h_{1}=\{6,3\}, h_{2}=\{9,2\}, h_{3}=\{5,3\}$, and $h_{4}=\{8,7\}$ be four HMFNs. Assume that $C\left(h_{i}, h_{j}\right)(i, j=$ $1,2,3,4, i \neq j)$ is compatibility between $h_{i}$ and $h_{j}$, then we have

$$
\begin{gathered}
\operatorname{HMFPG}\left(h_{1}, h_{1}, h_{1}\right)=\{6,4.5502,3.6326,3\}, \\
\operatorname{HMFPG}\left(h_{1}, h_{2}, h_{3}\right) \\
=\{6.2359,4.9282,4.6333,3.8400, \\
\quad 3.6643,3.1291,2.9962,2.6132\}, \\
\operatorname{HMFPG}\left(h_{1}, h_{2}, h_{4}\right) \\
=\{7.4367,7.1329,5.3207,
\end{gathered}
$$$$
5.15613 .9287,3.8333,3.1880,3.1220\} \text {. }
$$

According to Definition 4, we have

$$
\begin{gathered}
s\left(h_{1}\right)=s\left(h_{2}\right)=4.2426, \quad s\left(h_{3}\right)=3.8730, \\
s\left(h_{4}\right)=7.4833, \\
s\left(\operatorname{HMFPG}\left(h_{1}, h_{1}, h_{1}\right)\right)=4.1238, \\
s\left(\operatorname{HMFPG}\left(h_{1}, h_{2}, h_{3}\right)\right)=3.8581, \\
s\left(\operatorname{HMFPG}\left(h_{1}, h_{2}, h_{4}\right)\right)=4.6488 .
\end{gathered}
$$

Therefore, $\operatorname{HMFPG}\left(h_{1}, h_{1}, h_{1}\right) \neq h_{1}$, which implies that the HMFPG operator is not idempotent.

Furthermore, because $s\left(\operatorname{HMFPG}\left(h_{1}, h_{2}, h_{3}\right)\right)<s\left(h_{3}\right)<$ $s\left(h_{2}\right)=s\left(h_{1}\right)$, which implies that the DHFPA operator is not bounded.

Finally, because $s\left(\operatorname{HMFPG}\left(h_{1}, h_{1}, h_{1}\right)\right)>s\left(\operatorname{HMFPG}\left(h_{1}\right.\right.$, $\left.\left.h_{2}, h_{3}\right)\right)$ and $s\left(\operatorname{HMFPG}\left(h_{1}, h_{1}, h_{1}\right)\right)<s\left(\operatorname{HMFPG}\left(h_{1}, h_{2}, h_{4}\right)\right)$, we have HMFPG $\left(h_{1}, h_{1}, h_{1}\right)>\operatorname{HMFPG}\left(h_{1}, h_{2}, h_{3}\right)$ and $\operatorname{HMFPG}\left(h_{1}, h_{1}, h_{1}\right) \prec \operatorname{HMFPG}\left(h_{1}, h_{2}, h_{4}\right)$.

Therefore, the HMFPG operator is not monotonic. 
Moreover, in the HMFPG operator, all of the arguments that are being aggregated are of equal importance. If we allow the arguments to have different weights, then we provide a generalization of the HMFPG operator by combining it with the generalized mean operator to obtain the weighted generalized hesitant multiplicativefuzzy power geometric (WGHMFPG) operator as follows.

Definition 23. Let $h_{i}=\left\{\rho_{h_{i}}\right\}(i=1,2, \ldots, n)$ be a collection of HMFNs, weighted generalized hesitant multiplicative fuzzy power geometric (WGHMFPG) operators

$$
\begin{aligned}
& \text { WGHMFPG }\left(h_{i} \mid i=1,2, \ldots, n\right) \\
& =\frac{1}{\lambda} \bigotimes_{i=1}^{n}\left(\lambda h_{i}{ }^{w_{i}\left(1+T\left(h_{i}\right)\right) / \sum_{i=1}^{n} w_{i}\left(1+T\left(h_{i}\right)\right)}\right),
\end{aligned}
$$

where

$$
T\left(h_{i}\right)=\sum_{\substack{j=1 \\ j \neq i}}^{n} w_{j} C\left(h_{i}, h_{j}\right)
$$

$$
\begin{gathered}
C\left(h_{i}, h_{j}\right) \\
=\left(\prod_{\rho_{i} \in h_{i}, \rho_{j} \in h_{j}}\left(\min \left\{\frac{\rho_{h_{i_{\sigma(i)}}}}{\rho_{h_{j_{\sigma(i)}}}} \frac{\rho_{h_{\sigma_{\sigma(i)}}}}{\rho_{h_{i_{\sigma(i)}}}}\right\}\right)\right)^{1 /|h|}, \\
|h|=\left|h_{i}\right|=\left|h_{j}\right|, \quad i, j=1,2, \ldots, n,
\end{gathered}
$$

with the conditions that $w_{i} \in[0,1]$ for $i=1,2, \ldots, n$, and $\sum_{i=1}^{n} w_{i}=1$.

Using HMFN operations and mathematical induction on $n$, (25) can be transformed into the following form:

$$
\begin{aligned}
& \operatorname{WGHMFPG}\left(h_{i} \mid i=1,2, \ldots, n\right) \\
& =\bigcup_{\rho_{i} \in h_{i}, 1,2, \ldots, n}\left\{\frac{\left(\rho^{*}\right)^{1 / \lambda}-\left(\rho^{*}-\rho^{\wedge}\right)^{1 / \lambda}}{\left(\rho^{*}-\rho^{\wedge}\right)^{1 / \lambda}}\right\},
\end{aligned}
$$

where

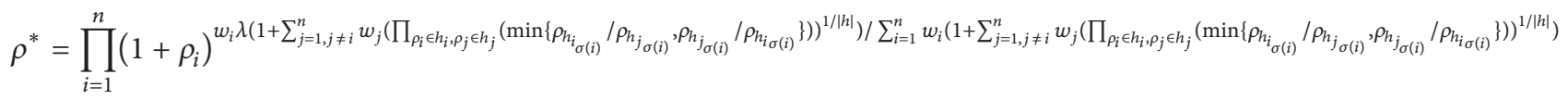

$$
\begin{aligned}
& \rho^{\wedge}=\prod_{i=1}^{n}\left(\left(1+\rho_{i}\right)^{\lambda}-1\right)^{w_{i}\left(1+\sum_{j=1, j \neq i}^{n} w_{j}\left(\prod_{\rho_{i} \in h_{i}, \rho_{j} \in h_{j}}\left(\min \left\{\rho_{h_{i_{\sigma(i)}}} / \rho_{h_{j(i)}}, \rho_{h_{j_{\sigma(i)}}} / \rho_{h_{i \sigma(i)}}\right\}\right)\right)^{1 /|h|}\right) / \sum_{i=1}^{n} w_{i}\left(1+\sum_{j=1, j \neq i}^{n} w_{j}\left(\prod_{\rho_{i} \in h_{i}, \rho_{j} \in h_{j}}\left(\min \left\{\rho_{h_{i(i)}} / \rho_{h_{j(i)}}, \rho_{h_{j(i)}} / \rho_{h_{i \sigma(i)}}\right\}\right)\right)^{1 /|h|}\right)} .
\end{aligned}
$$

3.2. Hesitant Multiplicative Fuzzy Power Ordered Weighted Geometric (HMFPOWG) Operators. Based on the POWG and HMFPG operators, we next define a hesitant multiplicative fuzzy power ordered weighted geometric (HMFPOWG) operator.

Definition 24. Let $h_{i}=\left\{\rho_{h_{i}}\right\}(i=1,2, \ldots, n)$ be a collection of HMFNs, a hesitant multiplicative fuzzy power ordered weighted geometric (HMFPOWG) operator:

$$
\operatorname{HMFPOWA}\left(h_{1}, h_{2}, \ldots, h_{n}\right)=\bigotimes_{i=1}^{n}\left(h_{\text {index }(i)}^{u_{i}}\right)
$$

where

$$
\begin{gathered}
u_{i}=g\left(\frac{R_{i}}{T V}\right)-g\left(\frac{R_{i-1}}{T V}\right), \quad R_{i}=\sum_{j=1}^{i} V_{\operatorname{index}(j)}, \\
T V=\sum_{i=1}^{n} V_{\operatorname{index}(i)}, \quad V_{\operatorname{index}(i)}=1+T\left(h_{\operatorname{index}(i)}\right), \\
T\left(h_{\operatorname{index}(i)}\right)=\sum_{\substack{j=1 \\
j \neq i}}^{n} C\left(h_{\operatorname{index}(i)}, h_{\operatorname{index}(j)}\right) .
\end{gathered}
$$

In Definition $14, h_{\text {index(i) }}$ is the $i$ th largest HMFN among all of the HMFNs, $h_{j}(j=1,2, \ldots, n), T\left(h_{\operatorname{index}(i)}\right)$ denotes the support of the $i$ th largest HMFN by all of the other HMFNs, $C\left(h_{\operatorname{index}(i)}, h_{\operatorname{index}(j)}\right)$ denotes the support of the $j$ th largest HMFN for the $i$ th largest HMFN, and Yager defined a BUM function $g:[0,1] \rightarrow[0,1]$, having the properties: $g(0)=1$, $g(1)=1$, and $g(x) \geq g(y)$ if $x \geq y$.

Using the operational laws of HMFNs, (29) can be further expressed as follows:

$$
\begin{aligned}
\operatorname{HMFPOWG}\left(h_{1}, h_{2}, \ldots, h_{n}\right) & \\
=\bigcup_{\rho_{\text {index }(i)} \in h_{\text {index }(i)}, i=1,2, \ldots, n}\{ & \left(\prod_{i=1}^{n}\left(\rho_{\text {index }(i)}\right)^{u_{i}}\right) \\
\times & \left(\prod_{i=1}^{n}\left(1+\rho_{\text {index }(i)}\right)^{u_{i}}\right. \\
& \left.\left.-\prod_{i=1}^{n}\left(\rho_{\text {index }(i)}\right)^{u_{i}}\right)^{-1}\right\},
\end{aligned}
$$

where $u_{i}$ satisfies condition (30). 


\section{Approaches to Multiple Attribute Group Decision Making in Uncertain Environments}

In the following, we use the proposed hesitant multiplicative fuzzy power aggregation operators to develop some approaches to multiple attribute group decision making with hesitant multiplicative fuzzy information in uncertain environments:

For a multiple attribute group decision making problem with hesitant multiplicative fuzzy information, let $X=$ $\left\{x_{1}, x_{2}, \ldots, x_{n}\right\}$ be a set of $n$ alternatives which is to be compared and $G=\left\{g_{1}, g_{2}, \ldots, g_{m}\right\}$ a set of $m$ attributes, whose weight vector is $w=\left(w_{1}, w_{2}, \ldots, w_{m}\right)^{T}$, with $w_{j} \in$ $[0,1]$ for $j=1,2, \ldots, m$, and $\sum_{j=1}^{m} w_{j}=1$. And let $E=$ $\left\{e_{1}, e_{2}, \ldots, e_{s}\right\}$ be a set of $s$ decision makers, whose weight vector is $\omega=\left(\omega_{1}, \omega_{2}, \ldots, \omega_{s}\right)^{T}$, with $\omega_{q} \in[0,1]$ for $q=$ $1,2, \ldots, s$, and $\sum_{q=1}^{s} \omega_{q}=1$. The $s$ decision makers are authorized to give their preferences about these alternatives, the decision makers uses the Saaty's 1-9 scale to express their preferences. Let $A^{(q)}=\left(h_{i j}\right)^{(q)}$ be a hesitant multiplicative fuzzy decision matrix, where $\left(h_{i j}\right)^{(q)}=\left\{\bigcup_{\left(\rho_{i j}\right)^{(q)} \in\left(h_{i j}\right)^{(q)}}\left(\rho_{i j}\right)^{(q)}\right\}$ is an value provided by the decision maker $e_{q}$ with the attribute $g_{p}$, denoted by a HMFN that indicates all of the possible intensity degree that the alternative $x_{i}$ is priority with the attribute $g_{j}$. When all the performances of the alternatives are provided, the hesitant multiplicative fuzzy decision matrix $A^{(q)}=\left(h_{i j}\right)^{(q)}, q=1,2 \ldots, s, i=1,2, \ldots n$, $j=1,2, \ldots m$, can be constructed.

To obtain the ranking of the alternatives, we improve the method of $\mathrm{Xu}$ and Yager [24] and Xu and Wang [29]:

\section{Approach 1.}

Step 1. Calculate the supports measures between $s$ decision makers:

$$
\begin{aligned}
& \operatorname{Sup}\left(\left(h_{i j}\right)^{(p)},\left(h_{i j}\right)^{(q)}\right)=C\left(\left(h_{i j}\right)^{(p)},\left(h_{i j}\right)^{(q)}\right), \\
& p, q=1,2 \ldots, s ; \quad i=1,2, \ldots n, \quad j=1,2, \ldots m .
\end{aligned}
$$

Step 2. Use the weights $w_{q}$ of sdecision makers $e_{q}(q=$ $1,2, \ldots, s)$ to calculate the weighted support $T\left(\left(h_{i j}\right)^{(q)}\right)$ of HMFN $\left(h_{i j}\right)^{(q)}$ by the other decision makers $e_{p}$ denoted by $\operatorname{HMFNs}\left(h_{i j}\right)^{(p)}(p, q=1,2, \ldots, s$, and $p \neq q)$.

$$
\begin{gathered}
T\left(h_{i j}\right)^{(q)}=\sum_{\substack{p=1 \\
p \neq q}}^{s} w_{p} \operatorname{Sup}\left(\left(h_{i j}\right)^{(q)},\left(h_{i j}\right)^{(p)}\right), \\
p, q=1,2, \ldots s, \quad i=1,2, \ldots, n ; \quad j=1,2, \ldots m .
\end{gathered}
$$

Step 3. Utilize the WGHMFPG operator to aggregate all of the individual hesitant multiplicative fuzzy decision matrices
$A^{(q)}=\left(h_{i j}\right)^{(q)}$ into the collective hesitant multiplicative fuzzy decision matrix $A=\left(h_{i j}\right)_{n \times m}$ :

$$
\begin{aligned}
\left(h_{i j}\right) & =\operatorname{WGHMFPG}\left(\left(h_{i j}\right)^{(1)},\left(h_{i j}\right)^{(2)}, \ldots,\left(h_{i j}\right)^{(q)}\right) \\
& =\frac{1}{\lambda} \bigotimes_{q=1}^{s}\left(\lambda h_{i j}^{(q)}\right)^{w_{q}\left(1+T\left(h_{i j}^{(q)}\right)\right) / \sum_{q=1}^{s} w_{q}\left(1+T\left(h_{i j}^{(q)}\right)\right)} .
\end{aligned}
$$

Step 4. Then, we use Xu's GHHMWG operator to aggregate all of the preference values for $i$ alternatives $(i=1,2, \ldots, n)$ which indicates how the alternative $x_{i}$ is priority:

$$
\left(h_{i}\right)=\operatorname{GHHMWG}\left(\left(h_{i 1}\right),\left(h_{i 2}\right), \ldots,\left(h_{i m}\right)\right) \text {. }
$$

Step 5. Rank the $h_{i}(i=1,2, \ldots, n)$ in descending order using Definition 4.

Step 6. Rank all of the alternatives $x_{i}(i=1,2, \ldots, n)$ and then select the best alternative in accordance with the collective overall preference values $h_{i}(i=1,2, \ldots, n)$.

If the information regarding the weights of the decision makers and attributes is unknown, then we use the HMFPOWG operator to develop an alternative approach to the MAGDM problem with hesitant fuzzy information, which is described below.

\section{Approach 2.}

Step 1. Calculate the supports measures between $s$ decision makers:

$$
\begin{aligned}
& \operatorname{Sup}\left(\left(h_{i j}\right)^{\operatorname{index}(p)},\left(h_{i j}\right)^{\operatorname{index}(q)}\right) \\
& =C\left(\left(h_{i j}\right)^{\operatorname{index}(p)},\left(h_{i j}\right)^{\operatorname{index}(q)}\right),
\end{aligned}
$$

$$
p, q=1,2 \ldots, s ; \quad i=1,2, \ldots n, j=1,2, \ldots m \text {. }
$$

Step 2. Calculate the support $T\left(\left(h_{i j}\right)^{\operatorname{index}(q)}\right)$ of HMFN $\left(h_{i j}\right)^{\text {index }(q)}$ by the other decision makers $e_{\text {index }(p)}$ denoted by $\operatorname{HMFNs}\left(h_{i j}\right)^{\operatorname{index}(p)}(p, q=1,2, \ldots, s$, and $p \neq q)$.

$$
\begin{gathered}
T\left(h_{i j}\right)^{\operatorname{index}(q)}=\sum_{\substack{p=1 \\
p \neq q}}^{s} \operatorname{Sup}\left(\left(h_{i j}\right)^{\operatorname{index}(q)},\left(h_{i j}\right)^{\operatorname{index}(p)}\right), \\
p, q=1,2, \ldots s, \quad i=1,2, \ldots, n ; \quad j=1,2, \ldots m .
\end{gathered}
$$

Step 3. Calculate the weight. Use the weights $u_{q}=\left(u_{i j}\right)^{(q)}$ of $e_{\text {index }(q)}$ decision makers, that is, associated with the $q$ th largest $\operatorname{HFMN}\left(h_{i j}\right)^{\text {index }(q)}$, where

$$
\begin{gathered}
\left(u_{i j}\right)^{(q)}=g\left(\frac{\left(R_{i j}\right)^{(q)}}{T V_{i j}}\right)-g\left(\frac{\left(R_{i j}\right)^{(q-1)}}{T V_{i j}}\right), \\
\left(R_{i j}\right)^{(q)}=\sum_{p=1}^{q}\left(V_{i j}\right)^{\operatorname{index}(p)}, \quad T V_{i j}=\sum_{p=1}^{s}\left(V_{i j}\right)^{\operatorname{index}(p)},
\end{gathered}
$$




$$
\begin{gathered}
\left(V_{i j}\right)^{\operatorname{index}(p)}=1+T\left(h_{i j}\right)^{\operatorname{index}(p)}, \\
T\left(h_{i j}\right)^{\operatorname{index}(p)}=\sum_{\substack{r=1 \\
r \neq p}}^{s} C\left(\left(h_{i j}\right)^{\operatorname{index}(p)},\left(h_{i j}\right)^{\operatorname{index}(r)}\right) .
\end{gathered}
$$

Step 4. Use the GHMFPOWG operator to aggregate all of the individual hesitant multiplicative fuzzy decision matrices $A^{(q)}=\left(h_{i j}\right)^{(q)}$ into the collective hesitant multiplicative fuzzy decision matrix $A=\left(h_{i j}\right)_{n \times m}$ :

$$
\begin{aligned}
\left(h_{i j}\right) & =\operatorname{GHMFPOWG}\left(\left(h_{i j}\right)^{(1)},\left(h_{i j}\right)^{(2)}, \ldots,\left(h_{i j}\right)^{(q)}\right) \\
& =\frac{1}{\lambda} \bigotimes_{q=1}^{s}\left(\lambda h_{i j}^{\operatorname{index}(q)}\right)^{\left(\left(_{i j}\right)^{(q)}\right.} .
\end{aligned}
$$

Step 5. Calculate the supports measures between $m$ attributes:

$$
\begin{array}{r}
\operatorname{Sup}\left(h_{i \operatorname{index}(j)}, h_{i \operatorname{index}(k)}\right)=C\left(h_{i \operatorname{index}(j)}, h_{i \operatorname{index}(k)}\right), \\
i=1,2 \ldots, n ; \quad j, k=1,2, \ldots m,
\end{array}
$$

where $h_{i \text { index }(j)}$ is the $j$ th largest attribute of all the attributes for the alternative $x_{i}$.

Step 6. Calculate the support $T\left(h_{i \operatorname{index}(j)}\right)$ of HMFN $h_{i \operatorname{index}(j)}$ by the other attributes denoted by HMFNs $h_{i \operatorname{index}(t)}(j, t=$ $1,2, \ldots, m$, and $j \neq t)$.

$$
\begin{aligned}
T\left(h_{i \operatorname{index}(j)}\right) & =\sum_{\substack{t=1 \\
t \neq j}}^{m} \operatorname{Sup}\left(h_{i \operatorname{index}(j)}, h_{i \operatorname{index}(t)}\right), \\
j, t & =1,2, \ldots m, \quad i=1,2, \ldots, n .
\end{aligned}
$$

Step 7. Calculate the weight. Use the weights $v_{i j}$, that is, associated with the $j$ th largest $\operatorname{HFMN}\left(h_{i \text { index }(j)}\right)$, where

$$
\begin{gathered}
v_{i j}=g\left(\frac{R_{i j}}{T V_{i}}\right)-g\left(\frac{R_{i(j-1)}}{T V_{i}}\right), \quad R_{i j}=\sum_{k=1}^{j}\left(V_{i \operatorname{index}(k)}\right), \\
T V_{i}=\sum_{k=1}^{m}\left(V_{i \operatorname{index}(k)}\right), \quad V_{i \operatorname{index}(k)}=1+T\left(h_{i \operatorname{index}(k)}\right), \\
T\left(h_{i \operatorname{index}(k)}\right)=\sum_{\substack{l=1 \\
l \neq k}}^{m} C\left(h_{i \operatorname{index}(k)}, h_{i \operatorname{index}(l)}\right) .
\end{gathered}
$$

Step 8. Then, we use Xu's GHHMWG operator to aggregate all of the preference values for $i$ alternatives $(i=1,2, \ldots, n)$ which indicates how the alternative $x_{i}$ is priority:

$$
\left(h_{i}\right)=\operatorname{GHHMWG}\left(\left(h_{i 1}\right),\left(h_{i 2}\right), \ldots,\left(h_{i m}\right)\right) .
$$

Step 9. Rank the $h_{i}(i=1,2, \ldots, n)$ in descending order using Definition 4.
Step 10. Rank all of the alternatives $x_{i}(i=1,2, \ldots, n)$ and then select the best alternative in accordance with the collective overall preference values $h_{i}(i=1,2, \ldots, n)$.

\section{Illustrative Example}

Our methods is a good way to those people who in the decision organization do not like to use the values between 0 and 1 but would like to use Saaty's ratio scale. As urban traffic is heavy, complex, and changeable, travelers have difficulty in route choices. Driving is a complex task involving a variety of skills. The most important of these skills involve taking in and processing information and making quick decisions based on this information. Driver tasks are categorized into three main elements: control, guidance, and navigation. Therefore, selecting a safe path and keeping the vehicle in the proper lane are of great importance for the drivers. But it is hard to choose the most suitable one among the alternatives which dominate each other in different characteristics. In real world applications, all the parameters of the transportation problems may not be known precisely due to uncontrollable factors. This type of imprecise data is not always well represented by random variable selected from a probability distribution. Fuzzy number may represent this data. So, fuzzy decision making method is needed here and is studied by many authors $[43,44]$. For the application, an expert team was formed. The criteria to be used in the model were determined by the expert team. Now the standard for route choice is average travel speed, density, average queue length, and level of service. The application performed is based on the steps provided in previous section and explained step by step together with the results. Suppose one driver wishes to plan and execute a trip. After preliminary screening, four routes (alternatives) $x_{i}(i=1,2,3,4)$ remain on the candidate list. Three experts $e_{k}(k=1,2,3)$ from a committee to act as decision makers, whose weight vector is $w=(0.3,0.3,0.4)^{T}$. Four attributes are under consideration: (1) average travel speed is computed by dividing the length of the highway, street section, or segment under consideration by the average travel time of the vehicles traversing it, $\left(G_{1}\right) ;(2)$ density is the number of vehicles (or pedestrians) occupying a given length of a lane or roadway at a particular instant. For the computations, density is averaged over time and is usually expressed as vehicles per mile (veh/mi) or passenger cars per mile ( $\mathrm{pc} / \mathrm{mi}),\left(G_{2}\right) ;(3)$ the average queue length, at the beginning of red, the queue length is zero and increases to its maximum value at the end of the red period. Then the queue length decreases until the arrival line intersects the service line, when the queue length equals zero. $\left(G_{3}\right)$ (4) Level of service (LOS) is a quality measure describing operational conditions within a traffic stream. $\left(G_{4}\right)$. The weight vector of the attributes $G_{j}(j=1,2,3,4)$ is $w=$ $(0.15,0.20,0.20,0.45)^{T}$, the results of which are the hesitant multiplicative sets. The experts $e_{k}(k=1,2,3)$ evaluate the routes (alternatives) $x_{i}(i=1,2,3,4)$ with respect to the attributes $G_{j}(j=1,2,3,4)$ and construct the following three hesitant multiplicative fuzzy decision matrices $A_{p}^{(q)}=$ $\left(h_{i j}\right)_{p}^{(q)}(q=1,2,3, p=1,2,3,4)$ (see Tables 1, 2, and 3). 
TABLE 1: The hesitant multiplicative fuzzy decision matrix $A^{(1)}$.

\begin{tabular}{lcccc}
\hline & $G_{1}$ & $G_{2}$ & $G_{3}$ & $G_{4}$ \\
\hline$x_{1}$ & $\left\{1, \frac{1}{3}\right\}$ & $\left\{\frac{2}{5}, \frac{1}{3}, \frac{1}{5}\right\}$ & $\left\{\frac{2}{3}, \frac{1}{3}\right\}$ & $\{9\}$ \\
$x_{2}$ & $\left\{\frac{1}{5}\right\}$ & $\{9,7,5\}$ & $\{4,2\}$ & $\{1\}$ \\
$x_{3}$ & $\{2,1\}$ & $\left\{\frac{1}{6}\right\}$ & $\left\{1, \frac{2}{3}\right\}$ & $\{6\}$ \\
$x_{4}$ & $\left\{2,1, \frac{1}{2}\right\}$ & $\{7,5,3\}$ & $\{5\}$ & $\left\{\frac{1}{3}\right\}$ \\
\hline
\end{tabular}

TABLE 2: The hesitant multiplicative fuzzy decision matrix $A^{(2)}$.

\begin{tabular}{ccccc}
\hline & $G_{1}$ & $G_{2}$ & $G_{3}$ & $G_{4}$ \\
\hline$x_{1}$ & $\left\{1, \frac{1}{3}, \frac{1}{5}\right\}$ & $\left\{1, \frac{1}{3}\right\}$ & $\left\{\frac{1}{2}, \frac{1}{3}\right\}$ & $\left\{\frac{15}{2}\right\}$ \\
$x_{2}$ & $\left\{1, \frac{1}{2}\right\}$ & $\{8,7\}$ & $\left\{1, \frac{1}{2}\right\}$ & $\left\{\frac{2}{3}\right\}$ \\
$x_{3}$ & $\{3,1\}$ & $\left\{\frac{1}{2}, \frac{1}{3}\right\}$ & $\{3,1\}$ & $\{4\}$ \\
$x_{4}$ & $\{1\}$ & $\{6,4\}$ & $\{8,6,5\}$ & $\left\{\frac{1}{2}\right\}$ \\
\hline
\end{tabular}

TABLE 3: The hesitant multiplicative fuzzy decision matrix $A^{(3)}$.

\begin{tabular}{lcccc}
\hline & $G_{1}$ & $G_{2}$ & $G_{3}$ & $G_{4}$ \\
\hline$x_{1}$ & $\left\{1, \frac{1}{2}\right\}$ & $\left\{1, \frac{2}{3}\right\}$ & $\left\{1, \frac{1}{2}\right\}$ & $\{8\}$ \\
$x_{2}$ & $\left\{\frac{1}{2}, \frac{1}{3}\right\}$ & $\{7,4\}$ & $\{3,2,1\}$ & $\left\{\frac{3}{2}\right\}$ \\
$x_{3}$ & $\{4,2\}$ & $\left\{\frac{1}{3}, \frac{1}{5}, \frac{1}{6}\right\}$ & $\left\{1, \frac{2}{3}\right\}$ & $\{3\}$ \\
$x_{4}$ & $\{3,2\}$ & $\{8,7,5\}$ & $\{7,4\}$ & $\left\{\frac{1}{5}\right\}$ \\
\hline
\end{tabular}

Assume that the weights of the decision makers and attributes are known. We use Approach 1 to select the route.

Step 1. Calculate the supports measures between $s$ decision makers:

$$
\begin{aligned}
& \operatorname{Sup}\left(\left(h_{i j}\right)^{(p)},\left(h_{i j}\right)^{(q)}\right)=C\left(\left(h_{i j}\right)^{(p)},\left(h_{i j}\right)^{(q)}\right), \\
& p, q=1,2 \ldots, s ; \quad i=1,2, \ldots n, \quad j=1,2, \ldots m,
\end{aligned}
$$

which satisfy support conditions. Here, we gave two cases where all the decision makers are optimists or pessimists. (Actually, they are not.) The case mainly depends on the decision makers' risk preferences. Three decision makers have eight preference permutations: (1) Optimist, optimist, optimist; (2) optimist, optimist, pessimist; (3) optimist, pessimist, optimist; (4) pessimist, optimist, optimist; (5) pessimist, optimist, pessimist; (6) pessimist, pessimist, optimist; (7) optimist, pessimist, pessimist; (8) pessimist, pessimist, pessimist), denoted by OOO, OOP, OPO, POO, PPO, POP, $\mathrm{OPP}$, and PPP, respectively.
For simplicity, we denote $C\left(\left(h_{i j}\right)^{(p)},\left(h_{i j}\right)^{(q)}\right)$ by $C_{i j}^{(p q)}$ which refers to the supports between $\left(h_{i j}\right)^{(p)}$ and $\left(h_{i t}\right)^{(q)}$ in the following:

$$
\begin{aligned}
& C_{\text {optimists }}^{(12)}=C_{\text {optimists }}^{(21)}=\left[\begin{array}{llll}
0.5848 & 0.4309 & 0.8660 & 0.8571 \\
0.2828 & 0.8221 & 0.2500 & 0.6667 \\
0.8165 & 0.3816 & 0.4714 & 0.6667 \\
0.6300 & 0.8122 & 0.8046 & 0.6667
\end{array}\right], \\
& C_{\text {optimists }}^{(13)}=C_{\text {optimists }}^{(31)}=\left[\begin{array}{llll}
0.8736 & 0.3420 & 0.6667 & 0.8889 \\
0.4899 & 0.8537 & 0.5724 & 0.6667 \\
0.5000 & 0.7469 & 1.0000 & 0.5000 \\
0.3816 & 0.7211 & 0.7418 & 0.6000
\end{array}\right] \text {, } \\
& C_{\text {optimists }}^{(23)}=C_{\text {optimists }}^{(32)}=\left[\begin{array}{llll}
0.5109 & 0.7937 & 0.5774 & 0.9375 \\
0.5774 & 0.7591 & 0.4368 & 0.4444 \\
0.6124 & 0.5109 & 0.4714 & 0.7500 \\
0.3816 & 0.8012 & 0.8434 & 0.4000
\end{array}\right] \text {; } \\
& C_{\text {pessimists }}^{(12)}=C_{\text {pessimists }}^{(21)}=\left[\begin{array}{llll}
0.8434 & 0.6214 & 0.8660 & 0.8333 \\
0.2828 & 0.8595 & 0.2500 & 0.6667 \\
0.8165 & 0.4368 & 0.4714 & 0.6667 \\
0.6300 & 0.8012 & 0.8046 & 0.6667
\end{array}\right] \text {, } \\
& C_{\text {pessimists }}^{(13)}=C_{\text {pessimists }}^{(31)}=\left[\begin{array}{llll}
0.7631 & 0.3915 & 0.6667 & 0.8889 \\
0.4899 & 0.7084 & 0.7211 & 0.6667 \\
0.5000 & 0.7469 & 1.0000 & 0.5000 \\
0.4368 & 0.7211 & 0.7703 & 0.6000
\end{array}\right] \text {, } \\
& C_{\text {pessimists }}^{(23)}=C_{\text {pessimists }}^{(32)}=\left[\begin{array}{llll}
0.6437 & 0.6300 & 0.5774 & 0.9375 \\
0.5774 & 0.6586 & 0.3467 & 0.4444 \\
0.6124 & 0.5848 & 0.4714 & 0.7500 \\
0.4368 & 0.6999 & 0.7757 & 0.4000
\end{array}\right] \text {. }
\end{aligned}
$$

Step 2. Use the weights $w_{q}$ of $s$ decision makers $e_{q}(q=$ $1,2, \ldots, s)$ to calculate the weighted support $T\left(\left(h_{i j}\right)^{(q)}\right)$ of HMFN $\left(h_{i j}\right)^{(q)}$ by the other decision makers $e_{p}$ denoted by $\operatorname{HMFNs}\left(h_{i j}\right)^{(p)}(p, q=1,2, \ldots, s$, and $p \neq q)$.

$$
\begin{aligned}
T_{\text {optimists }}^{(1)} & =\left[\begin{array}{llll}
0.5249 & 0.2661 & 0.5265 & 0.6056 \\
0.2808 & 0.5881 & 0.3039 & 0.4667 \\
0.4449 & 0.4132 & 0.5414 & 0.4000 \\
0.3416 & 0.5321 & 0.5381 & 0.4400
\end{array}\right], \\
T_{\text {optimists }}^{(2)} & =\left[\begin{array}{llll}
0.3798 & 0.4467 & 0.4907 & 0.6250 \\
0.3158 & 0.5503 & 0.2497 & 0.3778 \\
0.4899 & 0.3188 & 0.3300 & 0.5000 \\
0.3416 & 0.5641 & 0.5787 & 0.3600
\end{array}\right], \\
T_{\text {optimists }}^{(3)} & =\left[\begin{array}{llll}
0.4153 & 0.3407 & 0.3732 & 0.5479 \\
0.3202 & 0.4839 & 0.3027 & 0.3333 \\
0.3337 & 0.3773 & 0.4414 & 0.3750 \\
0.2289 & 0.4567 & 0.4756 & 0.3000
\end{array}\right], \\
T_{\text {pessimists }}^{(1)} & =\left[\begin{array}{llll}
0.5583 & 0.3430 & 0.5265 & 0.6056 \\
0.2808 & 0.5412 & 0.3634 & 0.4667 \\
0.4449 & 0.4298 & 0.5414 & 0.4000 \\
0.3637 & 0.5288 & 0.5495 & 0.4400
\end{array}\right],
\end{aligned}
$$


TABLE 4: The collective hesitant multiplicative fuzzy decision matrix $A$ based on the optimists (OOO).

\begin{tabular}{|c|c|c|c|c|c|c|c|}
\hline \multicolumn{3}{|c|}{$e_{1}$} & \multicolumn{2}{|c|}{$e_{2}$} & \multicolumn{2}{|c|}{$e_{3}$} & \multirow[t]{2}{*}{$e_{4}$} \\
\hline \multirow{6}{*}{$x_{1}$} & $\{0.3318$ & 0.3889 & $\{0.3677$ & 0.4159 & & & \\
\hline & 0.4130 & 0.4506 & 0.4313 & 0.4553 & $\{0.3864$ & 0.4377 & \multirow{5}{*}{8.1095} \\
\hline & 0.4891 & 0.5194 & 0.4908 & 0.5059 & 0.4774 & 0.4811 & \\
\hline & 0.5363 & 0.5733 & 0.5194 & 0.5799 & 0.5457 & 0.5500 & \\
\hline & 0.6695 & 0.6936 & 0.6039 & 0.6419 & 0.6041 & $0.6991\}$ & \\
\hline & 0.7428 & $1.0000\}$ & 0.6990 & $0.7457\}$ & & & \\
\hline \multirow{6}{*}{$x_{2}$} & & & $\{4.9701$ & 5.1155 & $\{0.9414$ & 1.0514 & \multirow{6}{*}{1.0073} \\
\hline & & & 5.4600 & 5.6332 & 1.1968 & 1.2011 & \\
\hline & $\{0.3193$ & 0.3734 & 5.7853 & 5.9784 & 1.3332 & 1.3575 & \\
\hline & 0.3766 & $0.4436\}$ & 6.2385 & 6.4611 & 1.3628 & 1.5249 & \\
\hline & & & 7.0000 & 7.2771 & 1.5845 & 1.8013 & \\
\hline & & & 7.5240 & $7.8422\}$ & 1.8410 & $2.1217\}$ & \\
\hline \multirow{4}{*}{$x_{3}$} & $\{1.2590$ & 1.4815 & \multirow{4}{*}{$\begin{array}{r}\{0.2018 \\
0.2232 \\
0.2662\end{array}$} & \multirow{4}{*}{$\begin{array}{l}0.2175 \\
0.2409 \\
0.2961\}\end{array}$} & $\{0.7408$ & 0.8423 & \multirow{4}{*}{3.9100} \\
\hline & 1.5557 & 1.7288 & & & 0.8705 & 0.9092 & \\
\hline & 1.8741 & 2.1119 & & & 1.0000 & 1.0477 & \\
\hline & 2.2463 & $2.8645\}$ & & & 1.0868 & $1.2703\}$ & \\
\hline \multirow{9}{*}{$x_{4}$} & & & $\{3.9236$ & 4.3199 & & & \multirow{9}{*}{0.3045} \\
\hline & & & 4.3806 & 4.4636 & & & \\
\hline & & & 4.6446 & 4.8687 & & & \\
\hline & $\{0.9672$ & 1.0581 & 5.0480 & 5.0657 & $\{4.5640$ & 4.7964 & \\
\hline & 1.2605 & 1.3986 & 5.1905 & 5.2756 & 5.1304 & 5.6320 & \\
\hline & 1.5622 & $1.7590\}$ & 5.3925 & 5.7111 & 5.9773 & $6.4854\}$ & \\
\hline & & & 5.8128 & 5.9529 & & & \\
\hline & & & 5.9742 & 6.2374 & & & \\
\hline & & & 6.6580 & $6.9816\}$ & & & \\
\hline
\end{tabular}

$$
\begin{aligned}
T_{\text {pessimists }}^{(2)} & =\left[\begin{array}{llll}
0.5105 & 0.4384 & 0.4907 & 0.6250 \\
0.3158 & 0.5213 & 0.2137 & 0.3778 \\
0.4899 & 0.3650 & 0.3300 & 0.5000 \\
0.3637 & 0.5203 & 0.5516 & 0.3600
\end{array}\right], \\
T_{\text {pessimists }}^{(3)} & =\left[\begin{array}{llll}
0.4220 & 0.3064 & 0.3732 & 0.5479 \\
0.3202 & 0.4101 & 0.3203 & 0.3333 \\
0.3337 & 0.3995 & 0.4414 & 0.3750 \\
0.2621 & 0.4263 & 0.4638 & 0.3000
\end{array}\right] .
\end{aligned}
$$

Step 3. Use the WGHMFPG operator to aggregate all of the individual hesitant multiplicative fuzzy decision matrices $A^{(q)}=\left(h_{i j}\right)^{(q)}$ into the collective hesitant multiplicative fuzzy decision matrix $A=\left(h_{i j}\right)_{n \times m}$ (See Tables 4 and 5).

Step 4. Then, we use Xu's GHHMWG operator to aggregate all of the preference values for $i$ alternatives $(i=1,2, \ldots, n)$ which indicates how the alternative $x_{i}$ is priority; we do not list the collective overall preference values because of limited space. Consider

$$
\left(h_{i}\right)=\operatorname{GHHMWG}\left(\left(h_{i 1}\right),\left(h_{i 2}\right), \ldots,\left(h_{i m}\right)\right) .
$$

Step 5. Calculate the score function of $h_{i}$; the numerical results obtained for these datasets are also listed in Table 6.
Case 1. Optimists (OOO): $s\left(x_{1}\right)=1.1157, s\left(x_{2}\right)=1.1068$, $s\left(x_{3}\right)=1.1125$, and $s\left(x_{4}\right)=0.8012$.

Case 2. Pessimists (PPP): $s\left(x_{1}\right)=1.1091, s\left(x_{2}\right)=1.1099$, $s\left(x_{3}\right)=1.1137$, and $s\left(x_{4}\right)=0.8013$.

Step 6. Rank all of the alternatives $x_{i}(i=1,2, \ldots, n)$ and then select the best alternative in accordance with the collective overall preference values $h_{i}(i=1,2, \ldots, n)$.

Case 1. Optimists (OOO): $s\left(x_{1}\right)>s\left(x_{3}\right)>s\left(x_{2}\right)>s\left(x_{4}\right)$.

Case 2. Pessimists (PPP): $s\left(x_{3}\right)>s\left(x_{2}\right)>s\left(x_{1}\right)>s\left(x_{4}\right)$.

From the Table 6, we can see the selection of the best alternative mainly depends on the decision makers' risk preferences. If three decision makers are optimists, they will select number 1 route, but if decision makers are optimists, they will choose number 3 route.

Moreover, when we change the parameter $\lambda$, we can obtain the different results (Tables 7 and 8).

We now present a figure to clearly demonstrate how the score values vary as the parameter $\lambda$ increases and the aggregation arguments are kept fixed (see Figures 1 and 2). In Figure 1, we choose all the decision makers' risk preferences are optimistic. We can find that scores of each route decrease as the values of $\lambda$ change from 0 to 10 . 
TABLE 5: The collective hesitant multiplicative fuzzy decision matrix $A$ based on the pessimists (PPP).

\begin{tabular}{|c|c|c|c|c|c|c|c|}
\hline & \multicolumn{2}{|c|}{$e_{1}$} & \multicolumn{2}{|c|}{$e_{2}$} & \multicolumn{2}{|c|}{$e_{3}$} & \multirow[t]{2}{*}{$e_{4}$} \\
\hline \multirow{6}{*}{$x_{1}$} & $\{0.3274$ & 0.3870 & $\{0.3617$ & 0.4074 & & & \\
\hline & 0.4044 & 0.4422 & 0.4278 & 0.4529 & $\{0.3864$ & 0.4377 & \multirow{5}{*}{8.1095} \\
\hline & 0.4832 & 0.5256 & 0.4847 & 0.4950 & 0.4774 & 0.4811 & \\
\hline & 0.5310 & 0.5575 & 0.5144 & 0.5645 & 0.5457 & 0.5500 & \\
\hline & 0.6729 & 0.6805 & 0.5961 & 0.6356 & 0.6041 & $0.6991\}$ & \\
\hline & 0.7491 & $1.0000\}$ & 0.6863 & $0.7345\}$ & & & \\
\hline \multirow{6}{*}{$x_{2}$} & & & $\{4.9847$ & 5.1333 & $\{0.9555$ & 1.0723 & \multirow{6}{*}{1.0073} \\
\hline & & & 5.4799 & 5.6571 & 1.2091 & 1.2180 & \\
\hline & $\{0.3193$ & 0.3734 & 5.8091 & 6.0068 & 1.3586 & 1.3787 & \\
\hline & 0.3766 & $0.4436\}$ & 6.2353 & 6.4614 & 1.3896 & 1.5641 & \\
\hline & & & 7.0000 & 7.2817 & 1.5981 & 1.8187 & \\
\hline & & & 7.5266 & $7.8503\}$ & 1.8685 & $2.1574\}$ & \\
\hline \multirow{4}{*}{$x_{3}$} & $\{1.2590$ & 1.4815 & \multirow{4}{*}{$\begin{array}{c}\{0.2024 \\
0.2241 \\
0.2667\end{array}$} & \multirow{4}{*}{$\begin{array}{l}0.2180 \\
0.2418 \\
0.2971\}\end{array}$} & $\{0.7408$ & 0.8423 & \multirow{4}{*}{3.9100} \\
\hline & 1.5557 & 1.7288 & & & 0.8705 & 0.9092 & \\
\hline & 1.8741 & 2.1119 & & & 1.0000 & 1.0477 & \\
\hline & 2.2463 & $2.8645\}$ & & & 1.0868 & $1.2703\}$ & \\
\hline \multirow{9}{*}{$x_{4}$} & & & $\{3.9166$ & 4.3101 & & & \multirow{9}{*}{0.3045} \\
\hline & & & 4.3667 & 4.4527 & & & \\
\hline & & & 4.6482 & 4.8500 & & & \\
\hline & $\{0.9695$ & 1.0614 & 5.0273 & 5.0770 & $\{4.5647$ & 4.7945 & \\
\hline & 1.2625 & 1.4019 & 5.1928 & 5.2725 & 5.1243 & 5.6307 & \\
\hline & 1.5636 & $1.7621\}$ & 5.3942 & 5.7227 & 5.9718 & $6.4730\}$ & \\
\hline & & & 5.8182 & 5.9645 & & & \\
\hline & & & 5.9675 & 6.2292 & & & \\
\hline & & & 6.6615 & $6.9842\}$ & & & \\
\hline
\end{tabular}

TABLE 6: Score values obtained by WGHMFPG operator based on preference permutations of experts and the ranking of alternatives.

\begin{tabular}{|c|c|c|c|c|c|}
\hline Preference permutations & $S\left(x_{1}\right)$ & $S\left(x_{2}\right)$ & $S\left(x_{3}\right)$ & $S\left(x_{4}\right)$ & Ranking \\
\hline OOO & 1.1157 & 1.1068 & 1.1125 & 0.8012 & $x_{1}>x_{3}>x_{2}>x_{4}$ \\
\hline OOP & 1.1129 & 1.1069 & 1.1125 & 0.8014 & $x_{1}>x_{3}>x_{2}>x_{4}$ \\
\hline $\mathrm{OPO}$ & 1.1104 & 1.1081 & 1.1137 & 0.8012 & $x_{3}>x_{1}>x_{2}>x_{4}$ \\
\hline POO & 1.1131 & 1.1084 & 1.1125 & 0.8012 & $x_{1}>x_{3}>x_{2}>x_{4}$ \\
\hline $\mathrm{PPO}$ & 1.1077 & 1.1098 & 1.1137 & 0.8012 & $x_{3}>x_{2}>x_{1}>x_{4}$ \\
\hline POP & 1.1136 & 1.1085 & 1.1125 & 0.8013 & $x_{1}>x_{3}>x_{2}>x_{4}$ \\
\hline OPP & 1.1099 & 1.1082 & 1.1137 & 0.8013 & $x_{3}>x_{1}>x_{2}>x_{4}$ \\
\hline PPP & 1.1091 & 1.1099 & 1.1137 & 0.8013 & $x_{3}>x_{2}>x_{1}>x_{4}$ \\
\hline
\end{tabular}

TABLE 7: Score values obtained by WGHMFPG operator based on the preference of OOO and the ranking of alternatives.

\begin{tabular}{llllll}
\hline OOO & $S\left(x_{1}\right)$ & $S\left(x_{2}\right)$ & $S\left(x_{3}\right)$ & $S\left(x_{4}\right)$ & \multicolumn{1}{c}{ Ranking } \\
\hline$\lambda=0.1$ & 1.1303 & 1.1316 & 1.1290 & 0.8099 & $x_{2}>x_{1}>x_{3}>x_{4}$ \\
$\lambda=0.3$ & 1.1272 & 1.1264 & 1.1256 & 0.8081 & $x_{1}>x_{2}>x_{3}>x_{4}$ \\
$\lambda=0.5$ & 1.1240 & 1.1210 & 1.1220 & 0.8062 & $x_{1}>x_{3}>x_{2}>x_{4}$ \\
$\lambda=1$ & 1.1157 & 1.1068 & 1.1125 & 0.8012 & $x_{1}>x_{3}>x_{2}>x_{4}$ \\
$\lambda=3$ & 1.0797 & 1.0452 & 1.0732 & 0.7796 & $x_{1}>x_{3}>x_{2}>x_{4}$ \\
$\lambda=5$ & 1.0427 & 0.9890 & 1.0401 & 0.7587 & $x_{1}>x_{3}>x_{2}>x_{4}$ \\
$\lambda=10$ & 0.9670 & 0.8936 & 0.9866 & 0.7170 & $x_{3}>x_{1}>x_{2}>x_{4}$ \\
\hline
\end{tabular}


TABLE 8: Score values obtained by WGHMFPG operator based on the preference of PPP and the ranking of alternatives.

\begin{tabular}{llllll}
\hline PPP & $S\left(x_{1}\right)$ & $S\left(x_{2}\right)$ & $S\left(x_{3}\right)$ & $S\left(x_{4}\right)$ & Ranking \\
\hline$\lambda=0.1$ & 1.1237 & 1.1347 & 1.1303 & 0.8101 & $x_{2}>x_{3}>x_{1}>x_{4}$ \\
$\lambda=0.3$ & 1.1206 & 1.1296 & 1.1268 & 0.8082 & $x_{2}>x_{3}>x_{1}>x_{4}$ \\
$\lambda=0.5$ & 1.1174 & 1.1242 & 1.1232 & 0.8063 & $x_{2}>x_{3}>x_{1}>x_{4}$ \\
$\lambda=1$ & 1.1091 & 1.1099 & 1.1137 & 0.8013 & $x_{3}>x_{2}>x_{1}>x_{4}$ \\
$\lambda=3$ & 1.0733 & 1.0480 & 1.0743 & 0.7797 & $x_{3}>x_{1}>x_{2}>x_{4}$ \\
$\lambda=5$ & 1.0368 & 0.9914 & 1.0411 & 0.7588 & $x_{3}>x_{1}>x_{2}>x_{4}$ \\
$\lambda=10$ & 0.9624 & 0.8950 & 0.9874 & 0.7171 & $x_{3}>x_{1}>x_{2}>x_{4}$ \\
\hline
\end{tabular}

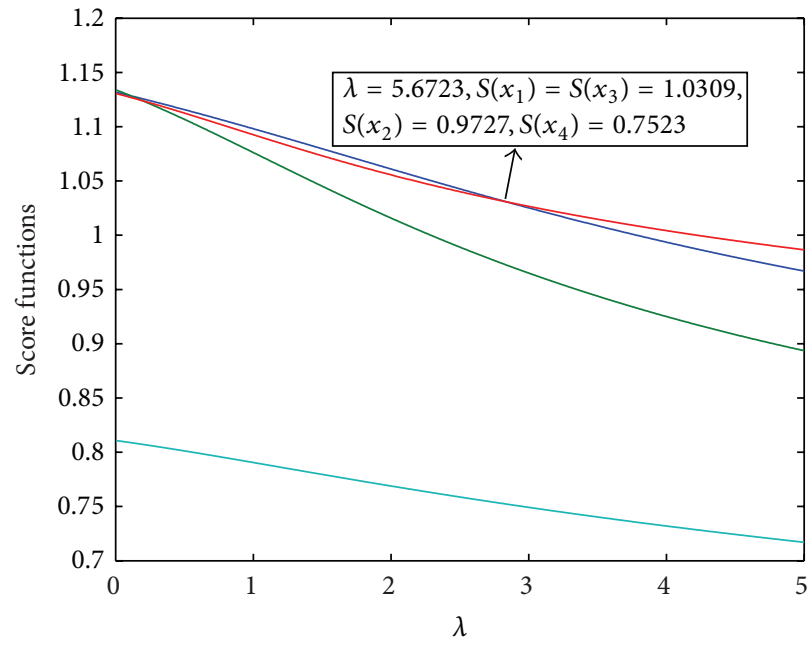

$\begin{array}{ll}x_{1} & -x_{3} \\ x_{2} & -x_{4}\end{array}$

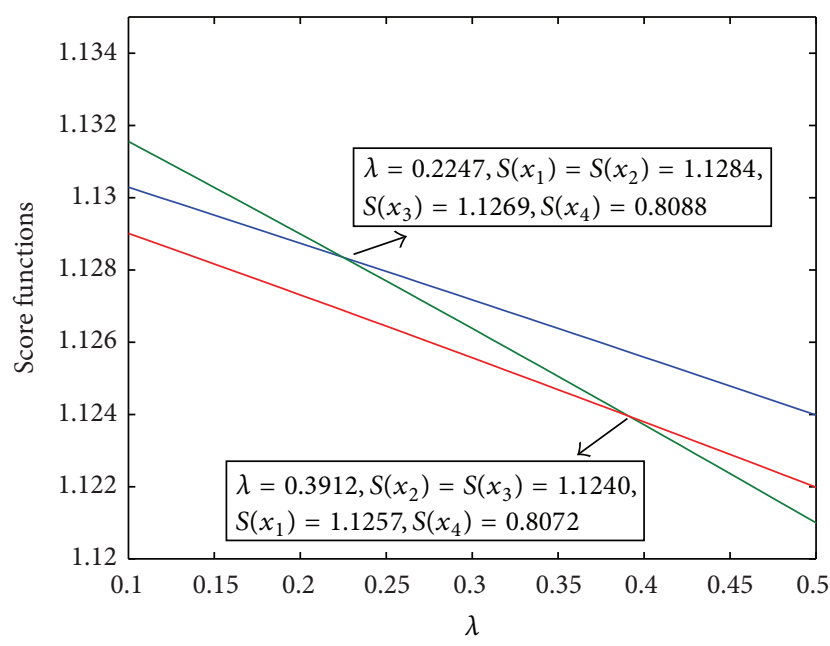

$-x_{1}$

(a)

(b)

Figure 1
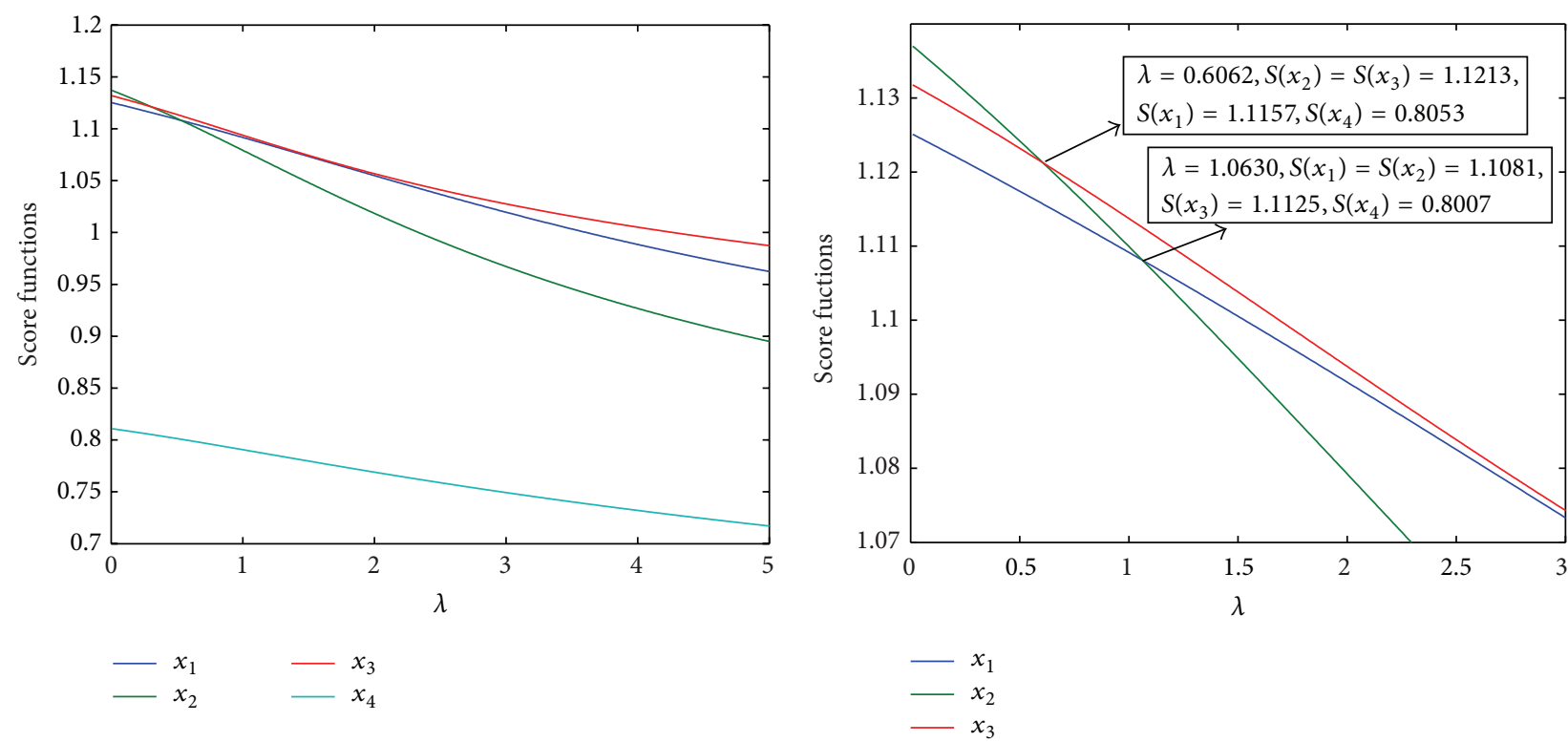

(a)

(b)

FIGURE 2: Variation of the score values with respect to the parameter $\lambda$. 
(1) If $0<\lambda<0.2247$, then we have $x_{2}>x_{1}>x_{3}>x_{4}$.

(2) If $0.2247<\lambda<0.3912$, then we have $x_{1}>x_{2}>x_{3}>$ $x_{4}$.

(3) If $0.3912<\lambda<5.6723$, then we have $x_{1}>x_{3}>x_{2}>$ $x_{4}$.

(4) If $5.6723<\lambda<10$, then we have $x_{3}>x_{1}>x_{2}>x_{4}$.

Figure 2 illustrates that scores of each route decrease as the values of $\lambda$ change from 0 to 10 with respect to pessimists of decision makers' risk preferences. From Figure 2, we can find the following.

(1) If $0<\lambda<0.6062$, then we have $x_{2}>x_{3}>x_{1}>x_{4}$.

(2) If $0.6062<\lambda<1.0630$, then we have $x_{3}>x_{2}>x_{1}>$ $x_{4}$.

(3) If $1.0630<\lambda<10$, then we have $x_{3}>x_{1}>x_{2}>x_{4}$.

\section{Conclusion}

In this paper, we have defined the compatibility measures between DHFEs and presented several new hesitant multiplicative fuzzy aggregation operators, including the HMFPG, WGHMFPG, and HMFPOWG operators. Moreover, we studied their properties, including their commutativity, idempotency, boundedness, and monotonicity. We have applied the proposed operators to develop two approaches to multiple attribute group decision making in hesitant multiplicative fuzzy environments. Finally, one typical real world example has been used to illustrate the application and verify the validity of our results.

\section{Conflict of Interests}

The authors declare that there is no conflict of interests regarding the publication of this paper.

\section{Acknowledgments}

The author is very grateful to the anonymous reviewers for their insightful and constructive comments and suggestions that have led to an improved version of this paper. This work is supported by the National Nature Science Foundation of China (no. 70971136).

\section{References}

[1] S. A. Orlovsky, "Decision-making with a fuzzy preference relation," Fuzzy Sets and Systems, vol. 1, no. 3, pp. 155-167, 1978.

[2] B. de Baets, H. de Meyer, B. de Schuymer, and S. Jenei, "Cyclic evaluation of transitivity of reciprocal relations," Social Choice and Welfare, vol. 26, no. 2, pp. 217-238, 2006.

[3] T. L. Saaty, The Analytic Hierarchy Process, McGraw-Hill, New York, NY, USA, 1980.

[4] D. Zhang, F. Xie, Y. Zhang, F. Dong, and K. Hirota, "Fuzzy analysis of community detection in complex networks," Physica A, vol. 389, no. 22, pp. 5319-5327, 2010.
[5] J. Che, J. Wang, and G. Wang, "An adaptive fuzzy combination model based on self-organizing map and support vector regression for electric load forecasting," Energy, vol. 37, pp. 657-664, 2012.

[6] E. Herrera-Viedma, S. Alonso, F. Chiclana, and F. Herrera, "A consensus model for group decision making with incomplete fuzzy preference relations," IEEE Transactions on Fuzzy Systems, vol. 15, no. 5, pp. 863-877, 2007.

[7] L. Zhou, H. Chen, and J. Liu, "Generalized power aggregation operators and their applications in group decision making," Computers and Industrial Engineering, vol. 62, no. 4, pp. 989999, 2012.

[8] R. R. Yager, "On ordered weighted averaging aggregation operators in multicriteria decision making," EEE Transactions on Systems, Man and Cybernetics B, vol. 18, no. 1, pp. 183-190, 1988.

[9] R. R. Yager, “Generalized OWA aggregation operators," Fuzzy Optimization and Decision Making, vol. 3, no. 1, pp. 93-107, 2004.

[10] D. F. Li, "The GOWA operator based approach to multiattribute decision making using intuitionistic fuzzy sets," Mathematical and Computer Modelling, vol. 53, no. 5-6, pp. 1182-1196, 2011.

[11] D. F. Li, "Multiattribute decision making method based on generalized OWA operators with intuitionistic fuzzy sets," Expert Systems with Applications, vol. 37, no. 12, pp. 8673-8678, 2010.

[12] D.-F. Li, L.-L. Wang, and G.-H. Chen, "Group decision making methodology based on the Atanassov's intuitionistic fuzzy set generalized OWA operator," International Journal of Uncertainty, Fuzziness and Knowledge-Based Systems, vol. 18, no. 6, pp. 801-817, 2010.

[13] Z. Xu and R. R. Yager, "Some geometric aggregation operators based on intuitionistic fuzzy sets," International Journal of General Systems, vol. 35, no. 4, pp. 417-433, 2006.

[14] Z. Xu, "Multi-person multi-attribute decision making models under intuitionistic fuzzy environment," Fuzzy Optimization and Decision Making, vol. 6, no. 3, pp. 221-236, 2007.

[15] G. W. Wei, "Some geometric aggregation functions and their application to dynamic multiple attribute decision making in the intuitionistic fuzzy setting," International Journal of Uncertainty, Fuzziness and Knowledge-Based Systems, vol. 17, no. 2, pp. 179-196, 2009.

[16] Y. Xu and H. Wang, "The induced generalized aggregation operators for intuitionistic fuzzy sets and their application in group decision making," Applied Soft Computing Journal, vol. 12, no. 3, pp. 1168-1179, 2012.

[17] G. Wei and X. Zhao, "Some induced correlated aggregating operators with intuitionistic fuzzy information and their application to multiple attribute group decision making," Expert Systems with Applications, vol. 39, no. 2, pp. 2026-2034, 2012.

[18] Z. X. Su, G. P. Xia, M. Y. Chen, and L. Wang, "Induced generalized intuitionistic fuzzy OWA operator for multi-attribute group decision making," Expert Systems with Applications, vol. 39, no. 2, pp. 1902-1910, 2012.

[19] Z. Xu, "Intuitionistic fuzzy aggregation operators," IEEE Transactions on Fuzzy Systems, vol. 15, no. 6, pp. 1179-1187, 2007.

[20] M. Xia and Z. Xu, "Hesitant fuzzy information aggregation in decision making," International Journal of Approximate Reasoning, vol. 52, no. 3, pp. 395-407, 2011.

[21] Z. S. Xu, M. Xia, and N. Chen, "Some hesitant fuzzy aggregation operators with their application in group decision making," Group Decision and Negotiation, vol. 22, no. 2, pp. 259-279, 2013. 
[22] G. Qian, H. Wang, and X. Feng, "Generalized hesitant fuzzy sets and their application in decision support system," KnowledgeBased Systems, vol. 37, pp. 357-376, 2013.

[23] R. R. Yager, “The power average operator," IEEE Transactions on Systems, Man, and Cybernetics A, vol. 31, no. 6, pp. 724-731, 2001.

[24] Z. Xu and R. R. Yager, "Power-geometric operators and their use in group decision making," IEEE Transactions on Fuzzy Systems, vol. 18, no. 1, pp. 94-105, 2010.

[25] L. Zhou and H. Chen, "A generalization of the power aggregation operators for linguistic environment and its application in group decision making," Knowledge-Based Systems, vol. 26, pp. 216-224, 2012.

[26] Z. Xu, "Approaches to multiple attribute group decision making based on intuitionistic fuzzy power aggregation operators," Knowledge-Based Systems, vol. 24, no. 6, pp. 749-760, 2011.

[27] Z. Zhang, “Generalized Atanassov's intuitionistic fuzzy power geometric operators and their application to multiple attribute group decision making," Information Fusion, vol. 14, no. 4, pp. 460-486, 2013.

[28] Z. S. Xu and X. Q. Cai, "Uncertain power average operators for aggregating interval fuzzy preference relations," Group Decision and Negotiation, vol. 21, no. 3, pp. 381-397, 2012.

[29] Y. J. Xu and H. M. Wang, "Approaches based on 2-tuple linguistic power aggregation operators for multiple attribute group decision making under ling uistic environment," Applied Soft Computing, vol. 11, no. 5, pp. 3988-3997, 2010.

[30] S.P. Wan, "Power average operators of trapezoidal intuitionistic fuzzy numbers and application to multi-attribute group decision making," Applied Mathematical Modelling, vol. 37, no. 6, pp. 4112-4126, 2013.

[31] Z. Zhang, "Hesitant fuzzy power aggregation operators and their application to multiple attribute group decision making," Information Sciences, vol. 234, pp. 150-181, 2013.

[32] M. Xia and Z. S. Xu, "Managing hesitant information in GDM problems under fuzzy and multiplicative preference relations," International Journal of Uncertainty, Fuzziness and KnowledgeBased Systems, vol. 21, no. 6, pp. 865-897, 2013.

[33] V. Torra, "Hesitant fuzzy sets," International Journal of Intelligent Systems, vol. 25, no. 6, pp. 529-539, 2010.

[34] S. Miyamoto, "Multisets and fuzzy multisets," in Soft Computing and Human-Centered Machines, Z. Q. Liu and S. Miyamoto, Eds., pp. 9-33, Springer, Berlin, Germany, 2000.

[35] S. Miyamoto, "Fuzzy multisets and their generalizations," in Multiset Processing, C. S. Caludeetal, Ed., vol. 2235 of Lecture Notes in Computer Science, pp. 225-235, Springer, Berlin, Berlin, Germany, 2001.

[36] R. R. Yager, "On the theory of bags," International Journal of General Systems, vol. 13, no. 1, pp. 23-37, 1987.

[37] Y. Jiang, Z. Xu, and X. Yu, "Compatibility measures and consensus models for group decision making with intuitionistic multiplicative preference relations," Applied Soft Computing, vol. 13, pp. 2075-2086, 2013.

[38] L. Wang, M. Ni, and L. Zhu, "Correlation measures of dual hesitant fuzzy sets," Journal of Applied Mathematics, vol. 2013, Article ID 593739, 13 pages, 2013.

[39] B. Zhu, Z. Xu, and M. Xia, "Dual hesitant fuzzy sets," Journal of Applied Mathematics, vol. 2012, Article ID 879629, 13 pages, 2012.

[40] J. M. Merigó and A. M. Gil-Lafuente, "The induced generalized OWA operator," Information Sciences. An International Journal, vol. 179, no. 6, pp. 729-741, 2009.
[41] H. W. Liu and G. J. Wang, "Multi-criteria decision-making methods based on intuitionistic fuzzy sets," European Journal of Operational Research, vol. 179, no. 1, pp. 220-233, 2007.

[42] Z. Xu and M. Xia, "Distance and similarity measures for hesitant fuzzy sets," Information Sciences, vol. 181, no. 11, pp. 2128-2138, 2011.

[43] C. M. Pintea, C. P. Sitar, M. Hajdu-Macelaru, and P. Petrica, "A hybrid classical approach to a fixed-charged transportation problem," Hybrid Artificial Intelligent Systems, Springer, vol. 7208, pp. 557-566, 2012.

[44] S. Molla-Alizadeh-Zavardehi, M. Hajiaghaei-Keshteli, and R. Tavakkoli-Moghaddam, "Solving a capacitated fixed-charge transportation problem by artificial immune and genetic algorithms with a Prüfer number representation," Expert Systems with Applications, vol. 38, no. 8, pp. 10462-10474, 2011. 


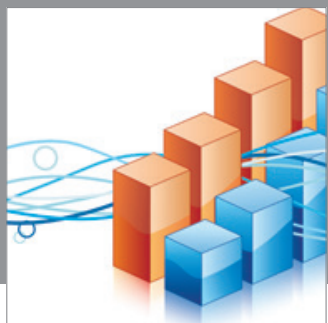

Advances in

Operations Research

mansans

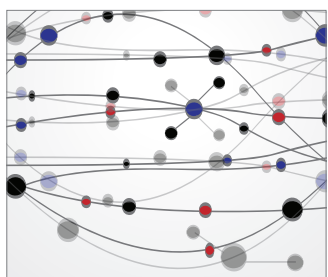

The Scientific World Journal
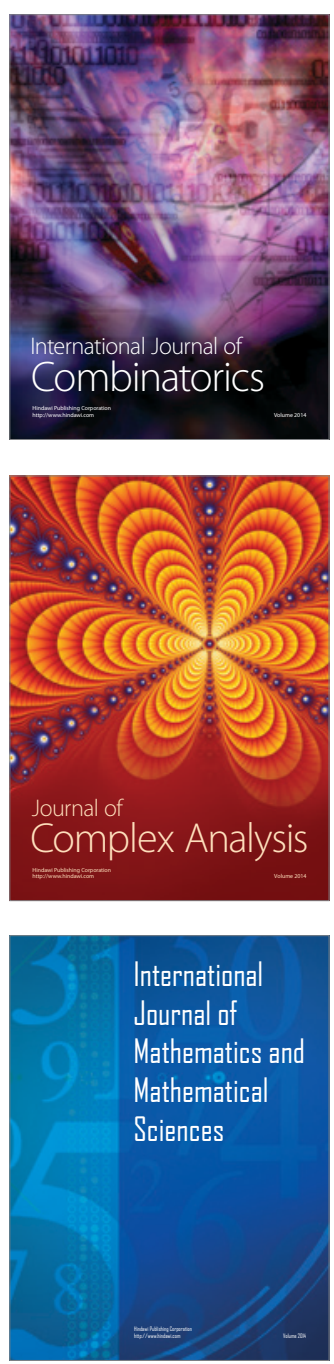
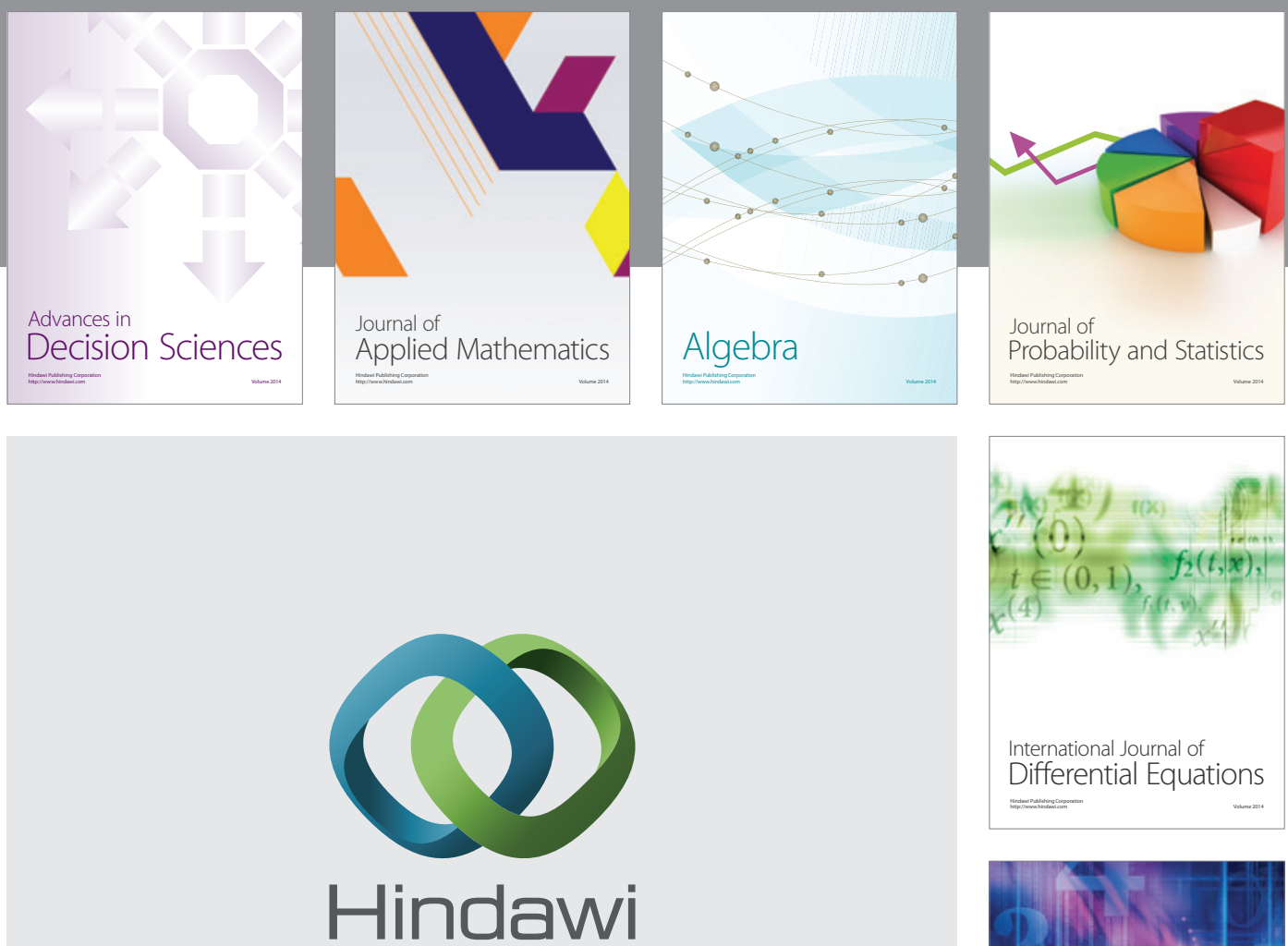

Submit your manuscripts at http://www.hindawi.com
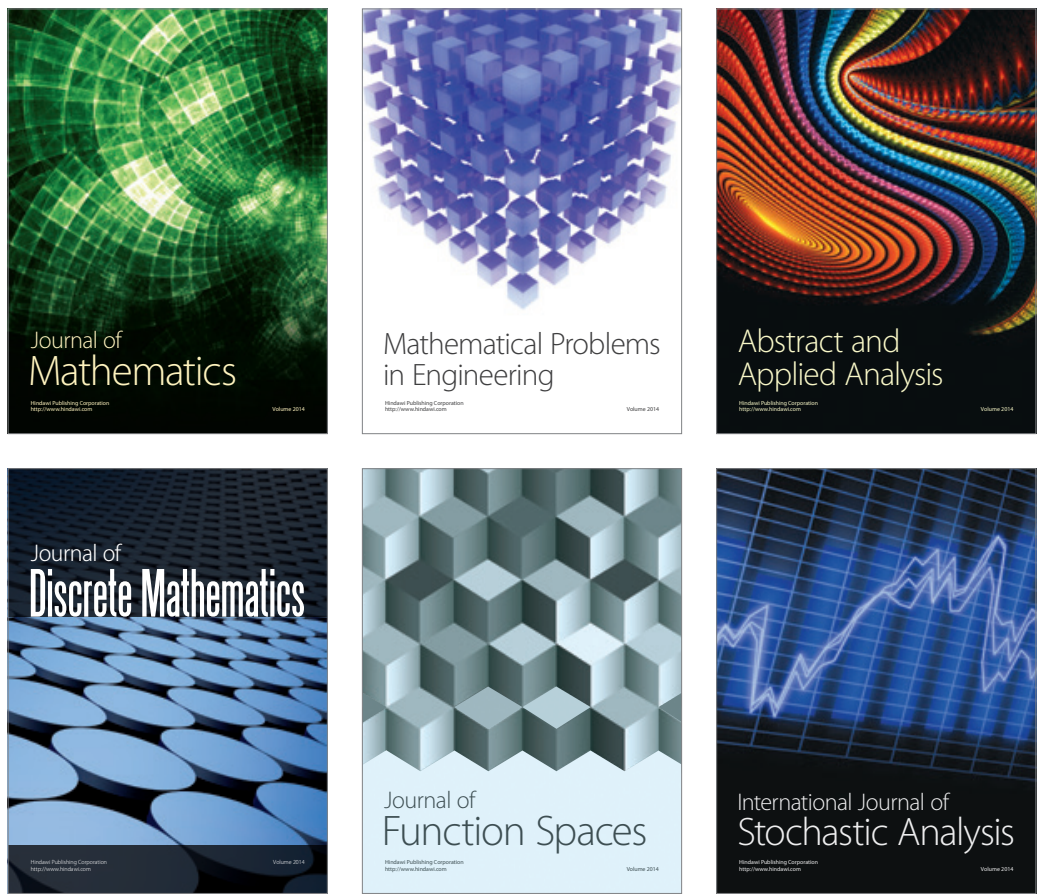

Journal of

Function Spaces

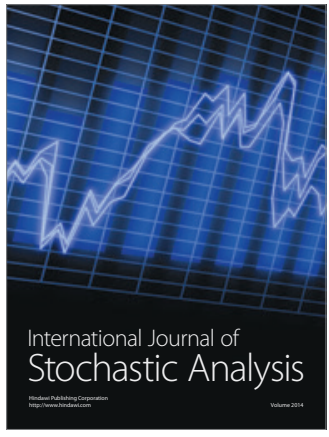

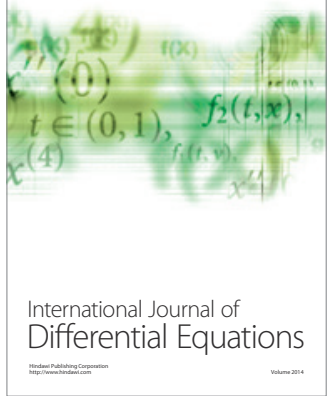
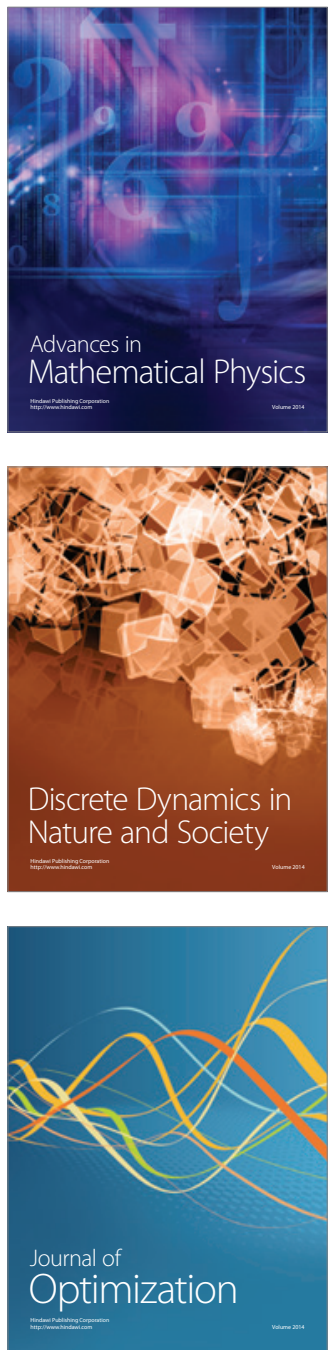